\title{
Second Asian Consensus on Irritable Bowel Syndrome
}

\begin{abstract}
Kok Ann Gwee, ${ }^{1}$ Sutep Gonlachanvit, ${ }^{2 *}$ Uday C Ghoshal, ${ }^{3}$ Andrew S B Chua, ${ }^{4}$ Hiroto Miwa, ${ }_{1}^{5}$ Justin Wu, ${ }^{6}$ Young-Tae Bak, ${ }^{7}$ Oh Young Lee, ${ }^{8}$ Ching-Liang Lu, ${ }^{9}$ Hyojin Park, ${ }^{10}$ Minhu Chen, ${ }^{11}$ Ari F Syam, ${ }^{12}$ Philip Abraham, ${ }^{13}$ Jose Sollano, ${ }^{14}$ Chi-Sen Chang, ${ }^{15}$ Hidekazu Suzuki, ${ }^{16}$ Xiucai Fang, ${ }^{17}$ Shin Fukudo, ${ }^{18}$ Myung-Gyu Choi, ${ }^{19}$ Xiaohua Hou, ${ }^{20}$ and Michio Hongo ${ }^{21}$

${ }^{1}$ Department of Medicine, Yong Loo Lin School of Medicine, National University of Singapore, and Gleneagles Hospital, Singapore; ${ }^{2}$ Center of Excellence on Neurogastroenterology and Motility, Department of Medicine, Faculty of Medicine, Chulalongkorn University, Bangkok, Thailand; ${ }^{3}$ Department of Gastroenterology, Sanjay Gandhi Postgraduate Institute of Medical Sciences, Lucknow, India; ${ }^{4}$ Gastro Centre, Ipoh, Malaysia; ${ }^{5}$ Division of Gastroenterology, Department of Internal Medicine, Hyogo College of Medicine, Mukogawa-cho, Nishinomiya, Hyogo, Japan; ${ }^{6}$ Department of Medicine and Therapeutics, Faculty of Medicine, The Chinese University of Hong Kong, New Territories, Hong Kong; ${ }^{7}$ Department of Internal Medicine, Korea University College of Medicine, Seoul, Korea; ${ }^{8}$ Department of Gastroenterology, College of Medicine, Hanyang University, Seoul, Korea; ${ }^{9}$ Endoscopy Center for Diagnosis and Treatment, Taipei Veterans General Hospital, Taipei, Taiwan; ${ }^{10}$ Division of Gastroenterology, Gangnam Severance Hospital, Yonsei University College of Medicine, Seoul, Korea; ${ }^{11}$ Department of Gastroenterology and Hepatology, The First Affiliated Hospital of Sun Yat-sen University, Guangzhou, China; ${ }^{12}$ Division of Gastroenterology, Departement of Internal Medicine, Faculty of Medicine, Universitas Indonesia, Cipto Mangunkusumo Hospital, Jakarta, Indonesia; ${ }^{13}$ Division of Gastroenterology, P D Hinduja Hospital, Mumbai, India; ${ }^{14}$ Department of Internal Medicine, Division of Gastroenterology, University of Santo Tomas, Manila, Philippine; ${ }^{15}$ Taichung Veterans General Hospital, Taiwan Boulevard, Taichung City, Taiwan; ${ }^{16}$ Department of Gastroenterology and Hepatology, Tokai University School of Medicine, Isehara, Kanagawa, Japan; ${ }^{17}$ Department of Gastroenterology, Peking Union Medical College Hospital, Chinese Academy of Medical Sciences and Peking Union Medical College, Beijing, China; ${ }^{18}$ Department of Behavioral Medicine, Tohoku University Graduate School of Medicine, Aoba Sendai, Japan; ${ }^{19}$ Division of Gastroenterology and Hepatology, Department of Internal Medicine, The Catholic University of Korea, Seoul, Korea; ${ }^{20}$ Union Hospital of Tongji Medical College, Huazhong University of Science and Technology, Wuhan, China; and ${ }^{21}$ Department of Medicine, Kurokawa General Hospital, Kurokawa, Miyagi, Japan
\end{abstract}

\section{Background/Aims}

There has been major progress in our understanding of the irritable bowel syndrome (IBS), and novel treatment classes have emerged. The Rome IV guidelines were published in 2016 and together with the growing body of Asian data on IBS, we felt it is timely to update the Asian IBS Consensus.

\section{Methods}

Key opinion leaders from Asian countries were organized into 4 teams to review 4 themes: symptoms and epidemiology, pathophysiology, diagnosis and investigations, and lifestyle modifications and treatments. The consensus development process was carried out by using a modified Delphi method.

\section{Results}

Thirty-seven statements were developed. Asian data substantiate the current global viewpoint that IBS is a disorder of gut-brain interaction. Socio-cultural and environmental factors in Asia appear to influence the greater overlap between IBS and upper gastrointestinal symptoms. New classes of treatments comprising low fermentable oligo-, di-, monosacharides, and polyols diet, probiotics, non-absorbable antibiotics, and secretagogues have good evidence base for their efficacy.

\section{Conclusions}

Our consensus is that all patients with functional gastrointestinal disorders should be evaluated comprehensively with a view to holistic management. Physicians should be encouraged to take a positive attitude to the treatment outcomes for IBS patients.

(J Neurogastroenterol Motil 2019;25:343-362)

\section{Key Words}

Asia; Constipation; Diarrhea; Intestines; Irritable bowel syndrome

Received: March 5, 2019 Revised: May 13, 2019 Accepted: June 24, 2019

$\otimes$ This is an Open Access article distributed under the terms of the Creative Commons Attribution Non-Commercial License (http://creativecommons. org/licenses/by-nc/4.0) which permits unrestricted non-commercial use, distribution, and reproduction in any medium, provided the original work is properly cited.

*Correspondence: Sutep Gonlachanvit, MD

Center of Excellence on Neurogastroenterology and Motility, Department of Medicine, Faculty of Medicine, Chulalongkorn University, Bangkok 10330, Thailand Tel: +66-2-256-4265, Fax: +66-2-252-7839, E-mail: gsutep@hotmail.com 


\section{Introduction}

The first Asian Consensus on Irritable Bowel Syndrome (IBS) was published in $2010 .{ }^{1}$ Since then, there has been major progress in our understanding of this condition and novel treatment classes have emerged. The international standard for diagnostic criteria in functional gastrointestinal disorders (FGIDs) was updated with the release of the Rome IV documents in 2016. ${ }^{2}$ FGIDs are now described as disorders of gut-brain interaction, shifting the emphasis to the gut, with greater prominence given to the intestinal microenvironment. Furthermore, there is now recognition of the roles of cross-cultural differences, the socio-cultural and environmental factors in the development and manifestation of IBS. The Asian Neurogastroenterology and Motility Association (ANMA) felt it is appropriate to examine the literature from an Asian perspective and to update the Asian IBS Consensus.

\section{Methods}

On April 1, 2016, ANMA convened a working team of 21 key opinion leaders from Asian countries on the basis of their scientific activities and published articles on IBS. Participants were organized into 4 teams to review 4 themes: symptoms and epidemiology, pathophysiology, diagnosis and investigations, and lifestyle modifications and treatments. The consensus development process was carried out by using a modified Delphi method. ${ }^{3}$

The consensus team members collected and reviewed original publications on IBS (in English and other languages) since the first consensus, through available global and domestic online literaturesearch systems. Manual search was also performed for publications that were not available online. Other important original and review articles from Asia and other parts of the world were also collected and reviewed. New publications that were published during the consensus process were also reviewed. Each team then generated 6 to 12 consensus statements through intra- and inter-team e-mail discussions.

On March 22, 2017, the working team met in Osaka during the ANMA Scientific Congress. All statements were presented along with supporting evidence, debated, and modified based on feedback. A grade of evidence was applied to every statement according to the GRADE Working Group. ${ }^{4}$ The final complete set of statements was subsequently circulated to all 21 members for anonymous voting. All members were asked to choose 1 of the following 6 levels of agreement on each statement: (a) accept completely, (b) accept with minor reservation, (c) accept with major reservation, (d) reject with major reservation, (e) reject with minor reservation, and (f) reject completely. The members were also asked to provide comments to each statement, if any. When the proportion of members who voted (a) or (b) was greater than or equal to $80.0 \%$, the statement was regarded as acceptable and a consensus was considered to have been reached.

\section{Team 1: Symptoms and Epidemiology}

Statement 1: Bowel-related symptoms in IBS consist of abdominal pain, bloating, or discomfort that is either improved or aggravated by passing stool or flatus. The symptoms can be associated with change in stool form or frequency and other symptoms including urgency, straining, and feeling of incomplete defecation.

Grade of evidence: moderate

Level of agreement: a. $80.9 \%$; b. $0.0 \%$; c. $14.3 \%$; d. $0.0 \%$; e. $4.8 \%$; f. $0.0 \%$

These characteristics of IBS symptoms are derived from the original studies by Manning and by Thompson. ${ }^{5,6}$ In the subsequent diagnostic criteria for IBS (Rome I to III), abdominal pain and/or discomfort are important components in the evaluation. In the Rome IV era, the term "discomfort" has been eliminated from the criteria because the term is thought to be ambiguous to patients. ${ }^{7}$ The current Rome IV definition for IBS required the patients to have recurrent abdominal pain, which is associated with defecation or a change in bowel habits. However, a recent global experts survey indicated that $53.8 \%$ felt that bloating was the most important feature of IBS, while only $25.6 \%$ felt that abdominal pain was. ${ }^{8}$ A study from China by using Rome III defined IBS, only $64.6 \%$ of them complained of recurrent abdominal pain and $44.2 \%$ with abdominal bloating alone. ${ }^{9}$ A large population-based internet survey from Japan also suggests that abdominal bloating has a great impact on the daily life of the patients with constipationpredominant IBS. ${ }^{10}$ Studies of IBS patients in India and Bangladesh suggested that frequency and/or severity of abdominal pain may not be so common, ranging from $33.0 \%$ to $70.0 \%$, which will result in a low prevalence of Rome IV IBS in India. ${ }^{11}$ In a multicenter Indian study using various IBS diagnostic criteria, the Manning criteria had the highest sensitivity (91.0\%), followed by Asian criteria (74.5\%), Rome I(68.0\%), Rome III (52.5\%), and Rome II (40.0\%) to diagnose IBS. ${ }^{12}$ The differences observed may be due to the fact that "abdominal pain" was not absolutely necessary for the diagnosis of IBS by both Manning and Asian criteria. Furthermore, "abdominal bloating" had been included in combination with 
"abdominal pain or discomfort" by the Asian criteria. ${ }^{1}$ Similar data has been reported from Romania. ${ }^{13}$ These data suggested that besides recurrent abdominal pain, abdominal bloating should also be included in the IBS diagnostic criteria, while the pain component in IBS may be de-emphasized in Asia.

Since the words for bloating symptom in several Asian countries have meanings overlapping with other abdominal symptoms, doctors in these countries should explore in detail to confirm whether the patient symptom is a real bloating symptom or not, according to the symptom concept described by the Rome committee.

Statement 2: The patient's bowel pattern should be described according to the Bristol stool form scale (BSFS) with consideration to stool frequency, straining, incomplete evacuation, and urgency.

\section{Grade of evidence: moderate}

Level of agreement: a. $71.4 \%$; b. $19.1 \%$; c. $9.5 \%$; d. $0.0 \%$; e. $0 \%$; f. $0.0 \%$

According to Western studies, stool frequency of normal bowel habit varies from 3 stools per week to 3 per day. ${ }^{14}$ However, wide variation in normal bowel frequency is noted throughout Asian countries. For example, normal stool frequency is once per day in Chinese and twice per day in Iranians. ${ }^{15,16}$ In Indian community, $90.0 \%$ of healthy subjects had more than 1 bowel movement per day, less than $1.0 \%$ had number of bowel movement fewer than 3 per week, while the median stool frequency was twice a day in IBS patients, regardless of whether they had constipation or diarrhea. ${ }^{17}$ It has consistently being shown that stool form rather than stool frequency better represent colonic transit time. ${ }^{18,19}$ Therefore, evaluating stool form using the Bristol scale is suggested as the tool of choice in the classification of IBS subtypes in Asia. Bristol stool scale has been reported to be a better marker of constipation and slow colonic transit. ${ }^{19-21}$ A recent validation study has also shown that IBS patients could more often be classified as having constipation- or diarrhea-predominant bowel pattern by the Bristol stool form and by the patients' own perception than by the stool frequency criteria. ${ }^{22}$

Statement 3: IBS patients may complain of meal-related symptoms, which include abdominal pain, bloating or distension.

Grade of evidence: moderate

Level of agreement: a. $76.1 \%$; b. $14.3 \%$; c. $4.8 \%$; d. $4.8 \%$; e. $0.0 \%$; f. $0.0 \%$

Several studies provide strong evidence that eating is an important trigger of symptoms in IBS patients. ${ }^{23-26}$ A study in Sweden required IBS patients to record in detail the timing of symptoms throughout the day for up to 6 weeks. This study demonstrated that pain was relieved with defecation on only $10.0 \%$ of occasions, whereas $50.0 \%$ of pain episodes developed within 90 minutes of eating. ${ }^{27}$ This study suggests that the pain experienced by IBS patients had a stronger temporal relationship to eating than to defecation. This could be a particular problem in Asia because Asian patients appear to present more frequently with upper abdominal pain than in Western patients. ${ }^{28,29}$ In a study from Taiwan, more than $50 \%$ of patients initially classified as dyspepsia were reclassified as IBS because their upper abdominal pain was exclusively relieved with defecation. ${ }^{30}$ We believe that it is important to highlight the relationship of symptoms to meals in IBS. Mistaking meal-related IBS symptoms as dyspepsia could lead to excessive investigation with tests, such as upper gastrointestinal (GI) endoscopy and ultrasound scans, inappropriate treatments, such as acid suppression, and unnecessary surgery, such as cholecystectomy. ${ }^{31,32}$

Statement 4: IBS is as prevalent in men as in women in most Asian countries.

Grade of evidence: moderate

Level of agreement: a. $80.9 \%$; b. $14.3 \%$; c. $4.8 \%$; d. $0.0 \%$; e. $0.0 \%$; f. $0.0 \%$

Globally the prevalence of IBS in women is approximately 1.5to 3-fold higher than those seen in men. ${ }^{33,34}$ In Western populations, women usually report more IBS symptoms than men, irrespective of the employed diagnostic criteria. ${ }^{35}$ However, if the IBS prevalence is stratified according to geographic region, no significant sex difference can be observed in South Asia, South America, and Africa. ${ }^{33}$ In Asia, most studies showed no gender difference (female vs male in India: $7.9 \%$ vs $6.9 \%, 4.3 \%$ vs $4 \%, 3.2 \%$ vs $4.8 \%$; Korea: $7.1 \%$ vs $6.0 \%$; Hong Kong: $6.6 \%$ vs $6.5 \%$; Pakistan: $13.1 \%$ vs $13.4 \%$; Taiwan: $21.8 \%$ vs $22.8 \%$; Singapore: $7.8 \%$ vs $9.4 \%$; Malaysia: $10.6 \%$ vs $10.5 \%$; Japan: $6.5 \%$ vs $5.5 \%) .^{28,36-38}$ Untill now, only 2 reports showed significantly higher IBS prevalence in females. 39,40

Statement 5: Dyspeptic symptoms including upper abdominal pain are prevalent in Asian IBS patients, and may result in a misdiagnosis of FD.

Grade of evidence: moderate

Level of agreement: a. $76.2 \%$; b. $14.2 \%$; c. $4.8 \%$; d. $0.0 \%$; e. $4.8 \%$; f. $0.0 \%$

In Asia the prevalence of dyspeptic symptoms in IBS patients has been variously reported (India 58.0\%, China 25.0-64.0\%, and South Korea 14.0\%). ${ }^{41-44}$ Furthermore Asian patients tend to present more with upper abdominal pain than Western patients. In a 
Taiwan study, Lu et al initially classified more than $50.0 \%$ of their patients as dyspepsia who were later reclassified as IBS when their upper abdominal pain was exclusively relieved with defecation. ${ }^{30}$ Similarly in a study performed in Singapore, $44.0 \%$ of patients who had functional chronic upper abdominal pain had IBS, while a later study demonstrated that more than $50.0 \%$ of IBS subjects localized their pain to the upper abdomen. ${ }^{45,46}$

Population-based studies demonstrated that $3.5 \%$ to $4.5 \%$ of the general adult population in India and Bangladesh have dyspepsia-IBS overlap. ${ }^{47,48}$ A community-based survey carried out involving 3000 people in Bangladesh, including both rural and urban populations, demonstrated that $42.0 \%$ of FD subjects had IBS and $27.0 \%$ IBS subjects had FD. ${ }^{48}$ Bowel symptoms frequency scores were higher in IBS-FD than IBS alone. ${ }^{47,48}$ In a hospital based study of patients with FD from China, postprandial fullness was a predictor of overlapping IBS. ${ }^{43}$ In a large study from Japan, abdominal bloating appears to be the most bothersome symptom in IBS with constipation (IBS-C) patients. ${ }^{10}$ Correspondingly, early satiety, epigastric pain, and bloating were important factors associated with IBS-FD overlap syndrome in Bangladesh. ${ }^{48}$ Bloating is a commonly encountered symptom in Asian IBS patients, in keeping with observations from Western countries. The challenge is not to misclassify these patients as functional dyspeptics when they actually suffer from IBS. An alternative is to view them as a spectrum of functional bowel disorders, focusing treatment on the main symptoms, or using combination therapy for the myriad of symptoms.

Statement 6: Stress relates to the exacerbation of IBS.

Grade of evidence: moderate

Level of agreement: a. $95.2 \%$; b. $4.8 \%$; c. $0.0 \%$; d. $0.0 \%$; e. $0.0 \%$; f. $0.0 \%$

Experience of psychosocial stress and exacerbation of GI symptoms in IBS patients show higher correlation than that in healthy individuals. ${ }^{49}$ IBS patients show more exaggerated colonic motility in response to experimental stress than healthy subjects. ${ }^{50}$ A meta-analysis showed that colorectal distension in IBS patient is more likely to activate the anterior cingulate cortex, amygdala, and midbrain, which are important brain regions for stress response, but deactivates the medial and lateral prefrontal cortex than healthy controls. ${ }^{51}$ Furthermore, the right dorsolateral prefrontal cortex in IBS patients was less activated than healthy controls when subjects were exposed to the situation with necessity of cognitive flexibility and stress-coping. ${ }^{52}$

Systematic review indicated that psychosocial stress likely alters gut microbiota, increases mucosal permeability, motility, and induces visceral hyperalgesia in IBS patients. ${ }^{53-55}$ Systematic review of epidemiology supports psychosocial stress (adverse life events) as one of risk factors of post-infection IBS (PI-IBS). ${ }^{56}$ When the severity of IBS increases, the impact of psychological distress in IBS patients increases. ${ }^{57}$ The interaction between IBS and psychological symptoms are bi-directional. In a 12-year prospective study, functional GI disorder including IBS and functional dyspepsia at onset were found to increase the risk of developing depression and anxiety, while. depressive or anxiety disorder was a risk factor for the development of IBS. ${ }^{58}$ A 1-year prospective study indicates that in the majority of patients it is likely that IBS leads to depression and anxiety than the other way around..$^{59}$

\section{Team 2: Pathophysiology}

Statement 7: IBS is a multi-dimensional disorder with a variable combination of gut dysbiosis, GI low grade inflammation, mucosal immune activation, increased gut permeability, food intolerance, GI dysmotility, visceral hypersensitivity, altered gut-brain interaction, genetic, and psychosocial factors.

Grade of evidence: moderate

Level of agreement: a. $80.9 \%$; b. $14.3 \%$; c. $4.8 \%$; d. $0.0 \%$; e. $0.0 \%$; f. $0.0 \%$

It is now appreciated that multiple pathophysiological mechanisms may operate in individual patients contributing to symptoms and their exacerbation, health care seeking behavior, and treatment response. The important role that the gut micro-environment plays in the pathophysiology has been increasingly recognized. ${ }^{60}$ In the recently published Rome IV guidelines, the term "functional" is de-emphasized, and FGIDs are now defined as "disorders of gutbrain interaction."

Statement 8: Gut microbial dysbiosis is associated with IBS, especially IBS with predominant diarrhea (IBS-D).

\section{Grade of evidence: moderate}

Level of agreement: a. $71.4 \%$; b. $23.8 \%$; c. $4.8 \%$; d. $0.0 \%$; e. $0.0 \%$; f. $0.0 \%$

Multiple case-control studies from Asia and elsewhere demonstrated fecal microbial dysbiosis among patients with IBS as compared to controls. ${ }^{61-63}$ Since a fecal sample might not be representative of the small bowel, a few studies assessed small bowel aspirate among patients with IBS as compared to controls and showed dysbiosis even in the upper gut of patients with IBS. ${ }^{64}$ Multiple studies using quantitative upper gut aspirate culture and glucose and lactulose hydrogen breath tests also revealed occurrence of small 
intestinal bacterial overgrowth (SIBO) more often among patients with IBS than healthy subjects. ${ }^{65}$ Moreover, multiple studies documenting improvement in IBS symptoms following treatment with antibiotics including rifaximin also supports the role of gut dysbiosis in pathogenesis of IBS. ${ }^{66,67}$ Patients with IBS-D more often had SIBO than other sub-types of IBS. ${ }^{63,67}$ However, a few studies showed that methane production on lactulose hydrogen breath test is associated with constipation and its reduction with rifaximin accelerates colon transit time and improves constipation suggesting role of gut microbial dysbiosis even in a subset of patients with IBSC. ${ }^{68,69}$

Statement 9: IBS is associated with immune activation, low grade gut inflammation, and increased gut permeability.

\section{Grade of evidence: high}

Level of agreement: a. $71.4 \%$; b. $28.6 \%$; c. $0.0 \%$; d. $0.0 \%$; e. $0.0 \%$; f. $0.0 \%$

A large body of evidence supports the presence of immune activation, low grade inflammation, and increased gut permeability in the pathogenesis of IBS, particularly in PI-IBS and the diarrheapredominant sub-type..$^{70-75}$ In a study from India, over-producer polymorphisms of IL-1 receptor antagonist (which controls inflammation) were found to be infrequent and under-producers frequent among patients with IBS than controls. ${ }^{76}$ The same study also revealed patients with SIBO had higher duodenal mucosal levels of IL-1 $\alpha$ and $\beta$ and the latter correlated with looser stools (Bristol type VI) and bloating. ${ }^{76}$ Another recent Indian study showed that altered immune activation in response to dysbiotic microbiota may promote intestinal inflammation in a subset of IBS patients. ${ }^{77} \mathrm{~A}$ Chinese study showed that IL-10, an anti-inflammatory cytokine level in serum, was significantly lower in SIBO-positive than negative IBS patients. ${ }^{78}$ Nerve growth factor is known to mediate visceral hypersensitivity and gut mucosal barrier dysfunction through interactions with mast cells and sensory nerves. In a recent Chinese study, elevated mucosal nerve growth factor has been suggested to interact with mast cells and sensory nerve fibers, contributing to visceral hypersensitivity and impaired gut barrier function in IBS-D. ${ }^{79}$

Statement 10: GI infection predisposes to development of IBS.

Grade of evidence: high

Level of agreement: a. $80.9 \%$; b. $14.3 \%$; c. $4.8 \%$; d. $0.0 \%$; e. $0.0 \%$; f. $0.0 \%$

More than half a century ago, Chaudhary and Truelove described occurrence of IBS like syndrome following acute GI infection. ${ }^{80}$ Subsequently, Gwee et $\mathrm{al}^{81}$ reported that $27.0 \%$ of patients with acute gastroenteritis from Sheffield, England continued to have symptoms sufficient to fulfill the criteria for IBS for 6 months. Four studies on PI-IBS have been reported from Asia to date. In one cohort study from Beijing, China, the incidence of IBS by Rome II criteria among 295 patients following bacillary dysentery was $8.1 \%$ compared to $0.8 \%$ among controls. ${ }^{75}$ In a study from Seoul investigating an outbreak of Shigella infection among 181 health-care workers, the odds ratio of developing IBS was calculated to be 2.9 at 1 year. ${ }^{82}$ A 3-year follow-up study from Korea showed that PIIBS may last for 3 years after onset. ${ }^{83} \mathrm{~A}$ recent study conducted in Bangladesh showed gastroenteritis patients developed PI-IBS and PI-FD more often than controls ( $16.5 \%$ vs $2.6 \%$ and $7.4 \%$ vs $0.6 \%$, respectively). ${ }^{84}$ The same study also showed that $9.0 \%$ of patients developing Rome criteria-positive IBS after acute gastroenteritis actually developed post-infectious malabsorption syndrome (tropical sprue).

PI-IBS is defined as new development of IBS following acute infectious diarrhea, characterized by 2 of the followings, (1) diarrhea, (2) vomiting, (3) fever, and (4) positive stool culture for enteropathogens. ${ }^{85}$ PI-IBS is usually of diarrhoea-predominant subtype. In Asia, post-infective malabsorption, previously known as Tropical sprue, should be considered as a differential diagnosis. ${ }^{86}$ SIBO has been proposed as a possible link between the 2 conditions. ${ }^{85}$

Statement 11: Visceral hypersensitivity plays an important role in the development of symptoms in IBS patients.

Grade of evidence: moderate

Level of agreement: a. $85.7 \%$; b. $9.5 \%$; c. $4.8 \%$; d. $0.0 \%$; e. $0.0 \%$; f. $0.0 \%$

Exaggerated visceral sensitivity is well known in patients with IBS as compared to controls based on studies on luminal distension using balloon and gas during colonoscopy and lactose hydrogen breath test. ${ }^{87,88}$ Such luminal distension has also been shown to reproduce patient's abdominal pain. Visceral hypersensitivity in patients with IBS spans beyond the colon. It has been demonstrated in the esophagus, stomach, duodenum, and ileum, suggesting that these patients have irritable gut syndrome. ${ }^{89}$ Studies from Asia, like those from the rest of the world, also demonstrated hypersensitivity beyond the gut such as bladder dysfunction and fibromyalgia among patients with IBS. In an Indian study, following $50 \mathrm{~g}$ lactose ingestion, IBS patients experienced symptoms more than healthy subjects though the amount of breath hydrogen exhaled was comparable between the 2 groups. ${ }^{89}$ A Chinese study also showed similar results. ${ }^{90}$ Another Chinese study demonstrated that cold water 
intake lowered the visceral perception threshold. ${ }^{91}$ Abdominal pain could be elicited in $78.0 \%$ of patients with IBS in Singapore by distending the rectum with air insufflation. ${ }^{92}$

Statement 12: Dysregulated entero-endocrine system may contribute to pathogenesis of IBS.

\section{Grade of evidence: low}

Level of agreement: a. $80.9 \%$; b. $4.8 \%$; c. $14.3 \%$; d. $0.0 \%$;

e. $0.0 \%$; f. $0.0 \%$

Evidence includes increased enterochromaffin cell numbers as well as rectal mucosal serotonin (5-hydroxytryptamine [5-HT]) in PI-IBS, presence of 5-HT-transporter-gene-linked polymorphic region mutation in IBS-C (in China and Korea), and altered serotonergic signaling (increased and decreased plasma serotonin levels in IBS-D and IBS-C respectively). ${ }^{71,93-95}$ Of particular interest in Asia is the possible role that $5-\mathrm{HT}_{3}$ receptors may play in chili induced abdominal symptoms associated with IBS. ${ }^{96}$ However, a recent study compared enterochromaffin cells numbers in the colon of IBS and controls from subjects in Norway and Thailand demonstrated increased enterochromaffin cell numbers in IBS patients compared to controls only in Norwegian patients but not in Thai patients. ${ }^{97}$

Statement 13: GI motility disturbances in IBS patients can arise from an exaggerated physiological response to environmental stimuli, such as meals and stressors.

Grade of evidence: high

Level of agreement: a. $80.9 \%$; b. $14.3 \%$; c. $0.0 \%$; d. $4.8 \%$;

e. $0.0 \%$; f. $0.0 \%$

Exaggerated gastro-colic reflex among patients with IBS is well known. In an American study, colonic spike and motor activity were higher following a meal among patients with IBS compared to healthy subjects. ${ }^{26}$ Diarrhea-predominant IBS patients have higher colonic motility than constipation-predominant subset. A Korean study showed that patients with diarrhea-predominant IBS showed higher colonic motility than those with constipation-predominant IBS. ${ }^{98}$ Lactose malabsorption are common among patients with IBS in Asia. An Indian study showed that though levels of breath hydrogen were comparable among patients with IBS and healthy controls, IBS patients showed greater frequency of symptom development following lactose load than healthy subjects. ${ }^{88}$ This may be related to greater degree of visceral hypersensitivity among IBS patients as has been demonstrated in a recent Chinese study. ${ }^{90} \mathrm{An}$ Indian study demonstrated induction of IBS symptoms following chili ingestion. ${ }^{99}$ A study from Thailand also showed that chili ingestion produced more abdominal pain and burning in IBS-D pa- tients than in healthy volunteers. ${ }^{100}$ Several Japanese studies showed that patients with IBS showed greater colonic motor response than healthy controls to experimental stress, and suggested that corticotropin releasing factor liberated from the hypothalamus to be the possible mediator. ${ }^{101,102}$

Statement 14: Some diarrhea-predominant IBS patients have been shown to have rapid GI transit, while some constipationpredominant IBS is associated with slow transit.

\section{Grade of evidence: high}

Level of agreement: a. $85.7 \%$; b. $4.8 \%$; c. $4.8 \%$; d. $0.0 \%$; e. $0.0 \%$; f. $4.8 \%$

A few landmark studies showed that stool form is determined largely by colon transit time. ${ }^{19}$ A recent study, however, showed that the number of bacteria in the small bowel also determines stool forms; larger the number of bacteria in the small bowel, the looser the stools. ${ }^{64}$ Patients with IBS-D have shorter colonic transit time than those with IBS-C. ${ }^{103,104}$ Colonic transit time has been reported to be faster in Asian populations such as in India, Hong Kong, and Taiwan than in the West. ${ }^{105,106}$

Statement 15: IBS patients can show altered brain activations in specific regions, which might be involved in the perception of pain and emotional arousal.

\section{Grade of evidence: low}

Level of agreement: a. $90.5 \%$; b. $9.5 \%$; c. $0.0 \%$; d. $0.0 \%$; e. $0.0 \%$; f. $0.0 \%$

Like somatic sensation, visceral sensation including that from the gut is primarily presented to sensory cortex. However, visceral sensation can also lead to varying degree of emotional arousal due to activation of the emotional arousal system (limbic system and paralimbic structures), particularly among patients with IBS. Due to advances in functional imaging studies using functional magnetic resonance imaging (fMRI) and positron emission tomography (PET), understanding of cerebral processing of visceral sensation in patients with IBS as compared to healthy controls have been possible.

A few Asian studies showed that patients with IBS have exaggerated cerebral activation and abnormal emotional area activation following visceral and somatic stimulation, which is agreement with the Western studies. A Japanese study using PET showed that colonic distension resulted in enhanced activation of specific brain regions, including the limbic system and prefrontal cortex. ${ }^{107} \mathrm{An}$ fMRI-based study from China showed that rectal balloon distension resulted in increased activity in the anterior cingulate cortex, 
insula, prefrontal cortex, and thalamus, more so among IBS patients than controls. ${ }^{108}$ A study from Singapore showed abnormal cerebral activation on $\mathrm{MMRI}$ in anticipation of rectal pain among IBS patients during rectal stimulation. ${ }^{109}$ Cerebral and emotional response to pain is well known to differ among males and females. A recent Indian study on male IBS subjects and healthy controls showed differential brain response to rectal balloon distension and among patients with IBS-C and IBS-D. ${ }^{110}$

Statement 16: Psychosocial factors have significant role in the development and aggravation of IBS symptoms.

Grade of evidence: moderate

Level of agreement: a. $80.9 \%$; b. $14.3 \%$; c. $4.8 \%$; d. $0.0 \%$; e. $0.0 \%$; f. $0.0 \%$

Several case-control studies both from the West and Asia showed that patients with IBS have more psychological co-morbidities than healthy subjects. ${ }^{111}$ It is important, however, to note that a cause and effect relationship cannot be assigned based on such casecontrol studies. Authors of a recent Australian study suggested that in most patients with functional GI disorders gut symptoms drives psychological morbidity rather than the brain being the primary origin of GI symptoms. ${ }^{59}$ However, studies on PI-IBS demonstrated that psychosocial co-morbidity are predictors of development of IBS following an episode of acute gastroenteritis. ${ }^{81}$ A Korean study showed that depressed women had greater severity of GI symptoms in relation to the degree of depression. ${ }^{12}$ Japanese studies also suggested role of psychosocial stress exacerbating IBS symptoms. ${ }^{113}$

Some of the Asian data, like the Western studies, do suggest a role of psychosocial factors determining consultation behavior among patients with functional GI disorders including IBS. Anxiety was the only independent predictor for medical consultation in a study from Hong Kong. ${ }^{114}$ In Pakistan, a high psychological distress score was a strong predictor of IBS in men, but not in women, while in India, there appeared to be more consulters in the higher socioeconomic classes. ${ }^{18,115}$ However, in Korea, India, and Japan, psychological factors appear to be less important to influence consultation for IBS. ${ }^{18,116,117}$ These data may suggest that psychological co-morbidity may influence health care seeking in addition to sociocultural factors.

Statement 17: Genetic factors can contribute to the development of IBS, and gene-environmental interactions need to be further investigated.

Grade of evidence: low

Level of agreement: a. $76.2 \%$; b. $14.2 \%$; c. $4.8 \%$; d. $4.8 \%$;

\section{e. $0.0 \%$; f. $0.0 \%$}

It is well known that functional GI disorders, including IBS, occurs more often in families having members affected with these conditions. Though it has been argued that this may be related to environmental and socio-cultural factors, a role of genetic factors has also been considered. Polymorphisms in several genes involved inflammation, immune regulation, antigen recognition, defense mechanisms, tissue repair, neuro-transmission, lactose malabsorption etc have been studied in Asia. ${ }^{118}$ However, most of these studies suffer from limitation due to inadequate power resulting from relatively small sample size.

\section{Team 3: Diagnosis and Investigations}

Statement 18: IBS is a condition characterized by recurrent abdominal pain/discomfort, occurring in association with defecation or a change in bowel habits, in the absence of organic causes that are detectable by routine medical tests.

\section{Grade of evidence: low}

Level of agreement: a. $80.9 \%$; b. $14.3 \%$; c. $4.8 \%$; d. $0.0 \%$; e. $0.0 \%$; f. $0.0 \%$

The Rome IV criteria eliminated the term "discomfort" to reduce ambiguity and improve consistency of the criteria across different languages. The frequency of abdominal pain should be at least 1 day per week during the past 3 months with onset at least 6 months earlier. In daily clinical practice, however, a pragmatic and flexible diagnostic approach should be adopted: pain is not universal in patients with IBS, who may have only abdominal discomfort or bloating as the predominant symptom, the threshold for symptom frequency and duration also needs validation in Asian countries. ${ }^{6,119}$

The BSFS is recommended as a reliable tool for evaluation of bowel habits. The subtyping of IBS is based on the stool consistency on days with abnormal bowel habits when the patients are not taking any medication used for the treatment of the bowel habit abnormalities. Based on the BSFS, IBS can be classified into IBS$\mathrm{D}$, IBS-C, mixed bowel habits, and unclassified. A recent study from Thailand suggested the BSFS type 3 is also associated with constipation. Thus, the correlation of BSFS with IBS classification in Asian patients may be different from that in the West. ${ }^{120-122}$

Statement 19: The diagnosis of IBS requires careful history taking with reference to the diagnostic criteria of IBS, physical examination, and investigations may be performed if indicated, but there is no single diagnostic or confirmatory test for IBS.

\section{Grade of evidence: low}


Level of agreement: a. $85.7 \%$; b. $4.8 \%$; c. $4.8 \%$; d. $4.8 \%$; e. $0.0 \%$; f. $0.0 \%$

For the majority of patients with IBS, a positive clinical diagnosis can be based on symptoms and physical examination, with limited investigations. Routine investigations are not warranted in all patients. However, a Canadian center analyzed the performance of symptom-based criteria in secondary-care centers and found a modest specificity of only $71-82 \%$ and positive predictive value of $<50 \%{ }^{123}$

Statement 20: Alarm features that needed to be excluded when considering the diagnosis of IBS include the presence of blood in the stools, unintended weight loss, anaemia, nocturnal symptoms, fever, abdominal mass, ascites, a family history of colorectal cancer, and age of onset $>50$ years.

\section{Grade of evidence: low}

Level of agreement: a. $76.2 \%$; b. $14.3 \%$; c. $9.5 \%$; d. $0.0 \%$; e. $0.0 \%$; f. $0.0 \%$

The presence of alarm features should prompt for investigations including colonoscopy, whereas the absence of alarm symptoms and negative physical examination are associated with lower likelihood of organic disease in patients with IBS symptoms. ${ }^{1}$ However, data to support this approach are weak. ${ }^{124,125}$

Statement 21: In the primary-care setting, a positive symptombased diagnosis of IBS is recommended to minimize unnecessary investigations. A step-wise approach, with special attention to the presence of alarm features and the judicious use of selected diagnostic tests to rule out organic disease, is recommended.

\section{Grade of evidence: low}

Level of agreement: a. $85.7 \%$; b. $9.5 \%$; c. $0.0 \%$; d. $0.0 \%$; e. $0.0 \%$; f. $4.8 \%$

In the primary-care setting, selected non-invasive laboratory tests to exclude organic causes in patients without alarm features include full blood counts with erythrocyte sedimentation rate, blood chemistry with C-reactive protein, and stool examination for occult blood and fecal calprotectin. ${ }^{126-129}$ Normal C-reactive protein and fecal calprotectin in patients with non-constipation IBS can help exclude inflammatory bowel disease.$^{130}$ Evidence to support this approach is however weak. ${ }^{7}$

Stool examination for intestinal parasites should be performed in countries with high prevalence of intestinal parasites. However, the association of intestinal parasites with symptoms of IBS is still controversial and limited. ${ }^{131}$
Statement 22: In the referral-center setting, recommended investigations include full blood counts, erythrocyte sedimentation rate, blood chemistry, C-reactive protein, thyroid function test, stool examination for occult blood, parasites and Clostridium difficile infection, and colonoscopy.

\section{Grade of evidence: low}

Level of agreement: a. $66.6 \%$; b. $23.8 \%$; c. $4.8 \%$; d. $0.0 \%$; e. $0.0 \%$; f. $4.8 \%$

Colonoscopy for exclusion of colorectal cancer is indicated in patients with symptom onset at age 50 years or older, regardless of other alarm features. In younger patients, colonoscopy is indicated in the presence of alarm symptoms or signs, positive family history of colorectal cancer, and poor symptom response to empiric medical therapy. ${ }^{1,132}$ Patients included in clinical trials must have a colonoscopy and/or other examinations as required by the entry criteria or study design.

Further work-up may be considered in selected patients for the diagnosis of other conditions such as SIBO, celiac disease, bile-acid diarrhea, malabsorption syndrome, and pancreatic or small bowel neoplasm. These investigations should be individualized according to the regional prevalence of each condition. ${ }^{64,85,133-135}$

Statement 23: Fecal evacuation disorder may present as constipation-predominant IBS.

\section{Grade of evidence: low}

Level of agreement: a. $85.7 \%$; b. $4.8 \%$; c. $4.8 \%$; d. $4.8 \%$; e. $0.0 \%$; f. $0.0 \%$

Normal defecation requires coordination between contraction of the abdominal muscles that increase intra-rectal pressure and relaxation of the pelvic floor including the anal sphincter. Pubo-rectal dyssynergia is a common type of fecal evacuation disorder (FED). Different types of pubo-rectal dyssynergia are characterized by lack of increase in intra-rectal pressure or reduction in residual pressure in the anal canal during attempted defecation. An Indian study showed that the Rome III criteria for IBS were equally fulfilled among patients with constipation with or without FED. ${ }^{136}$ In a Thai study, of 50 patients with FED, 29 (58.0\%) fulfilled Rome II criteria for IBS; patients with or without IBS demonstrated similar responses to biofeedback therapy. ${ }^{137}$ These Asian studies suggest that patients with FED may present as constipation-predominant IBS. $^{138}$

Statement 24: Wheat sensitivity or non-celiac gluten sensitivity (NCGS) and IBS patients are distinct entities although their symptoms may overlap. 
Grade of evidence: moderate

Level of agreement: a. $71.4 \%$; b. $14.3 \%$; c. $9.5 \%$; d. $0.0 \%$; e. $0.0 \%$; f. $4.8 \%$

NCGS is an increasingly recognized entity in the spectrum of gluten-related disorders, and is characterized by bowel symptoms similar to IBS. Evidence has emerged from several Asian countries for the presence of NCGS in patients fulfilling IBS criteria. ${ }^{133-135,13,140}$ The pathophysiology of NCGS is poorly understood and a causal relationship between NCGS and IBS is still a subject of debate. ${ }^{141}$ Moreover, the symptom benefit obtained from a gluten-free diet may be attributed to its low fermentable oligo-, di-, monosacharides, and polyols (FODMAP) content.

Statement 25: In addition to symptom severity, evaluation of health-related quality of life (QOL), functional impairment, psychological stressors and distress is recommended in the clinical evaluation of disease morbidity and monitoring of treatment response.

Grade of evidence: moderate

Level of agreement: a. $85.7 \%$; b. $0 \%$; c. $14.3 \%$; d. $0.0 \%$; e. $0.0 \%$; f. $0.0 \%$

IBS is associated with significant impairment in the QOL, social functioning, sleep, and psychological well-being. ${ }^{142-144}$ Validated questionnaires should be considered as supportive instruments for quantitative and objective assessment of quality-of-life impairment and psychological distress. Short form 36, EuroQol 5 dimension, Hospital Anxiety and Depression Scale, Patient Health Questionnaire, and IBS-QOL have been used in Asian studies.

\section{Team 4: Life Style Modifications and Treat- ments}

\section{Introduction/General Comments}

In the first Asian IBS consensus, ${ }^{1}$ it was generally agreed that the aims of IBS management are symptom relief as well as improving QOL, with the establishing of a good doctor-patient relationship being a cornerstone. Physicians were recommended to identify contributing factors and the patient's specific concerns, so that the management of IBS may be individualized. Specifically, all bothersome symptoms should be targeted, taking into account specific IBS subtypes, symptom severity, and contributing factors including psychosocial issues. It was generally agreed that these remain fundamental to effective management of IBS. Since the last iteration, there has been substantial new information in dietary and pharmacological management. ${ }^{145}$
Statement 26: A low FODMAPs diet could be helpful in IBS.

Grade of evidence: moderate

Level of agreement: a. $85.7 \%$; b. $4.8 \%$; c. $9.5 \%$; d. $0.0 \%$; e. $0.0 \%$; f. $0.0 \%$

As diet is a frequent concern, a detailed dietary history was commended. New data involving diets in Western populations suggest that a diet low in FODMAPs may be effective in improving bloating, flatulence, and abdominal pain. ${ }^{146,147}$ As these are nonabsorbable sugars, they are osmotically active, and subjected to fermentation in the colon, resulting in the production of metabolites and gases, that may contribute to causing diarrhea, abdominal pain, and bloating. Patients of all IBS subtypes had greater satisfaction with stool consistency while on the low-FODMAPs diet, while diarrhea-predominant IBS appeared to benefit from improved stool consistency and frequency. ${ }^{147}$ Specifically to Asian populations, the role of a low FODMAPs diet in the management of IBS requires further study as studies are lacking. ${ }^{148,149}$ While in some communities (eg, India with high prevalence of vegetarianism) diets may be high in FODMAPs, others may traditionally be relatively low (eg, China and Japan) ${ }^{48,148,149}$ Lactose as a FODMAP is of specific relevance to Asia as lactase deficiency is almost universal in Asians. ${ }^{88,150}$ However, as the average daily consumption is relatively low, the role of lactose-containing dairy foods in Asia is uncertain. ${ }^{48,151}$

Statement 27: Antispasmodic agents are efficacious for the treatment of abdominal pain in IBS.

Grade of evidence: high

Level of agreement: a. $85.7 \%$; b. $14.3 \%$; c. $0.0 \%$; d. $0.0 \%$; e. $0.0 \%$; f. $0.0 \%$

Meta-analysis of antispasmodics as well as several Asian clinical trials support the efficacy of this class of drugs to relief IBS symptoms, especially when abdominal pain is the predominant symptom. ${ }^{145,152-157}$ As a class, anti-spasmodics have a favorable profile with number needed to treat (NNT) of 5 and number needed to harm of 17.5. ${ }^{152}$ However, some antispasmodics may have anticholinergic side effects.

Statement 28: Antidiarrheal agents are effective in controlling diarrhea in IBS.

Grade of evidence: moderate

Level of agreement: a. $76.2 \%$; b. $14.3 \%$; c. $9.5 \%$; d. $0.0 \%$; e. $0.0 \%$; f. $0.0 \%$

Common antidiarrheal agents studied for the treatment of IBS were loperamide and smectite. Loperamide is an opioid agonist that is frequently used to control diarrhea both in infectious and 
non-infectious conditions. A limited number of randomized control trials (RCTs) are available that support its efficacy in IBS, and confidence in the estimate of effect was further limited by the small sample sizes. ${ }^{158-160}$ Data on the use in IBS of natural adsorbent clay compounds such as dioctahedral smectite that is frequently used to treat diarrhea in children, is very limited and suggests effect on abdominal discomfort or bloating. ${ }^{1,162}$

Statement 29: Some 5- $\mathrm{HT}_{3}$ antagonists are effective in IBS-D.

Grade of evidence: high

Level of agreement: a. $80.9 \%$; b. $14.3 \%$; c. $4.8 \%$; d. $0.0 \%$; e. $0.0 \%$; f. $0.0 \%$

Serotonin is a neurotransmitter functioning in GI sensation, motility, and secretion. In the GI tract, 5-HT receptor subtype 3 and 4 mediate key functions that have been targeted for amelioration of IBS symptoms. ${ }^{163} 5-\mathrm{HT}_{3}$ antagonists have been shown to slow intestinal transit and to decrease abdominal pain. ${ }^{164,165} \mathrm{Ex}-$ amples of 5- $\mathrm{HT}_{3}$ antagonists that have been tested in IBS are alosetron, ramosetron, and ondansetron. Alosetron encountered serious side effect of ischemic colitis and is now available only in the USA. Ramosetron was newly developed in Japan for the treatment of IBS-D. In a trial comparing ramosetron with placebo, patients with IBS-D treated with ramosetron showed significant improvements in global IBS symptoms, abdominal pain, and bowel habits. ${ }^{166} \mathrm{~A}$ Japanese study for the effect of ramosetron on IBS-D patients also showed significantly increased rate of symptom improvements in ramosetron group (47.0\%) than placebo group (27.0\%). ${ }^{167}$ In a recent randomized, placebo-controlled study of 576 Japanese women with IBS-D, $2.5 \mu \mathrm{g}$ ramosetron per day reduced abdominal pain and discomfort, increased stool consistency, and improved QOL as well as global IBS symptoms. ${ }^{168}$

Although in these studies, there have not been any reports regarding significant adverse reactions including ischemic colitis to this drug, significant proportions of 1 in 5 reported constipation after treatment of ramosetron. ${ }^{166-168}$ Ramosetron is also approved for managing patients with IBS-D in Japan, Korea, and Thailand. ${ }^{169}$ Ondansetron is an established anti-emetic with good safety record. In an investigator initiated RCT from the UK, a pragmatic approach was employed whereby starting at $4 \mathrm{mg}$ once a day, the dose could be titrated up to $8 \mathrm{mg} 3$ times a day, ondansetron was found to be more effective than placebo in improving loose stools, bowel frequency and urgency. ${ }^{170}$

Statement 30: Some serotonin 5- $\mathrm{HT}_{4}$ receptor agonists are effective in constipation-predominant IBS.
Grade of evidence: high

Level of agreement: a. $85.7 \%$; b. $9.5 \%$; c. $4.8 \%$; d. $0.0 \%$; e. $0.0 \%$; f. $0.0 \%$

Tegaserod is a partial $5-\mathrm{HT}_{4}$ agonist with high quality data from Asia for efficacy in IBS-C, both in women and men. ${ }^{171-173} \mathrm{Un}$ fortunately, a controversial alert by Food and Drug Administration regarding cardiovascular safety has led to its withdrawal from most countries. ${ }^{174}$ An alternative, prucalopride is a selective $5-\mathrm{HT}_{4}$ agonist, that has high quality efficacy data for relieving bloating, hard stool, and straining, symptoms commonly associated with IBSC. ${ }^{175-179}$ While prominent side effects include diarrhea, headache, abdominal pain, and nausea, no cardiovascular safety concerns have been reported. ${ }^{174,177}$ Studies involving tegaserod and prucalopride, including 3 involving Asian subjects, provide evidence of efficacy in male subjects. ${ }^{173,178,179}$

Statement 31: The effectiveness of probiotics has not been fully validated in IBS.

Grade of evidence: moderate

Level of agreement: a. $85.7 \%$; b. $4.8 \%$; c. $9.5 \%$; d. $0.0 \%$; e. $0.0 \%$; f. $0.0 \%$

Probiotics are live micro-organisms that confer health benefits. Several meta-analysis provide evidence that some probiotics have beneficial effect in IBS, but not all probiotics have demonstrated benefit. ${ }^{180}$ Thus, which species or combination was the most beneficial is unclear. Where a beneficial effect has been demonstrated, improvements in abdominal pain, bloating, and flatulence have been reported.

It is specifically noted that these meta-analyses were carried out on heterogeneous studies. While Lactobacillus rhamnosus GG has strong evidence in children, this was lacking in adult IBS patients. ${ }^{181,182}$ In a study of adult IBS patients, Bifidobacterium infantis was found to improve symptoms over placebo, whereas Lactobacillus salivarius did not. ${ }^{183}$ In a related study from the same investigators treatment with the same strain produced significant improvement of IBS symptoms only for intermediate dose. ${ }^{184,185}$ The authors emphasized the need for clinical data in the final dosage form and dose of a probiotic before confirming efficacy in clinical use. This was endorsed and emphasized in a recently published Asian consensus on probiotics. ${ }^{185}$

Statement 32: Antidepressants are effective for IBS, but it is unclear which patient will benefit.

Grade of evidence: moderate

Level of agreement: a. $71.4 \%$; b. $14.3 \%$; c. $14.3 \%$; d. $0.0 \%$; 


\section{e. $0.0 \%$; f. $0.0 \%$}

A meta-analysis of 16 RCTs, found RR of IBS symptom not improving with antidepressants vs placebo was 0.67 and NNT of $4 .^{186}$ The quality of the data appeared to be better for tricyclic antidepressant (TCA) than selective serotonin reuptake inhibitor (SSRI). Doses of TCA used in IBS trials were frequently below therapeutic range for depression; in particular, 3 Asian studies used low doses of TCAs. ${ }^{187-189}$ This suggests the possibility of a peripheral effect. On the other hand, doses of SSRIs used in IBS especially the studies from the West, were at anti-depressant levels. ${ }^{190,191}$ In one RCT of citalopram where non-depressed patients were excluded, there was no evidence of benefit. ${ }^{190}$ This suggests that SSRI may be acting at the central level. It should be noted that these agents are only used off label in many countries, and it is important to be familiar with known side-effects.

Statement 33: Secretagogues are effective in IBS-C.

Grade of evidence: high

Level of agreement: a. $85.7 \%$; b. $14.3 \%$; c. $0.0 \%$; d. $0.0 \%$;

e. $0.0 \%$; f. $0.0 \%$

Linaclotide, a guanylate cyclase-C agonist, with very low oral bioavailability, acts locally in the intestinal tract to stimulate fluid secretion, increase colonic transit, and inhibit colonic nociceptors. ${ }^{192-194}$ In Asia, a recent study with linaclotide $290 \mu \mathrm{g}$, involving close to 700 patients from China, found significant efficacy over placebo for abdominal pain (60.0\% vs $49.0 \%)$ and diarrhea was the commonest side effect $(9.0 \%) .{ }^{195}$ This reinforces the findings of 2 pivotal studies where abdominal pain endpoints were met by about $54.0 \%$ on linaclotide vs $36.0-42.0 \%$ on placebo. ${ }^{196-198}$ Similarly, the commonest adverse event of linaclotide was diarrhea (19.7\%). ${ }^{199}$

Lubiprostone is a luminally acting prostone that selectively activates the type- 2 chloride ion channel ( $\mathrm{ClC}-2$ chloride channel) expressed in the small intestinal epithelial cells, thereby increasing the amount of water content it the intestinal lumen. ${ }^{200}$ In Asia, efficacy of lubiprostone for IBS-C has been evaluated in only 42 patients in a Japanese study with only the $48 \mu \mathrm{g}$ dose showing superiority over placebo. ${ }^{201}$ Initial dose ranging studies had found that the $48 \mu \mathrm{g}$ dose was associated with more GI adverse events than the $16 \mu \mathrm{g}$ dose which was considered the optimal dose for efficacy and safety. ${ }^{202}$ Nausea was the commonest side effect, occurring in as many as $31 \%$, and is dose dependent. ${ }^{203}$ Furthermore, long-term safety data is available only for the $16 \mu \mathrm{g}$ dose, but not for the $48 \mu \mathrm{g}$ dose. $^{204} \mathrm{~A}$ recent systematic review and meta-analysis observed that while lubiprostone was efficacious in the short term, and except for bloating all other outcomes including abdominal pain did not ap- pear to be different from placebo. ${ }^{205}$

Statement 34: Non-absorbable antibiotics are effective in IBS.

Grade of evidence: high

Level of agreement: a. $47.6 \%$; b. $42.9 \%$; c. $9.5 \%$; d. $0.0 \%$;

e. $0.0 \%$; f. $0.0 \%$

Rifaximin is a rifamycin derived non-absorbable antibiotic which is associated with anti-inflammatory activity. Meta-analysis involving 5 high quality studies, found efficacy for global IBS symptoms, with secondary outcome analysis indicating that bloating could be the key symptom responding to rifaximin in nonconstipated IBS. ${ }^{206}$ Adverse effects were similar among patients receiving rifaximin or placebo in all studies. ${ }^{207}$ Repeat treatments with rifaximin also appear to be safe. ${ }^{208,209}$ While the role of antibiotics was premised on the presence of low-grade SIBO, none of the pivotal studies actually evaluated this. One study from China reported that identifying SIBO among patients with IBS criteria produced better outcome. ${ }^{210}$ A study from India employing norfloxacin similarly observed better response in those with demonstrable SIBO. ${ }^{66}$ However, data on the efficacy of rifaximin for IBS in Asia are lacking. One study from Hong Kong found that a 2-week course produced significant relief of symptoms in functional dyspepsia, but in this study, patients with overlapping IBS were actively excluded. ${ }^{211}$

Statement 35: Some complementary and alternative medicine (CAM) (specifically peppermint oil and Kampo) could be effective in treating IBS.

\section{Grade of evidence: low}

Level of agreement: a. $71.4 \%$; b. $14.3 \%$; c. $9.5 \%$; d. $0.0 \%$; e. $0.0 \%$; f. $4.8 \%$

Its heterogeneity makes it difficult to evaluate the efficacy of CAM as a single treatment class. The 4 commonest CAM treatments were evaluated. Chinese herbal medicine has the biggest evidence base and will be evaluated separately. Peppermint oil, thought to alleviate IBS symptoms by relaxing smooth muscles via calcium channels, has been shown in a meta-analysis to be efficacious for IBS. ${ }^{152}$ A review of Japanese herbal medicine (Kampo) found little clinical trial evidence for a role in IBS. ${ }^{212}$ Daikenchuto was reported to reduce symptoms of constipation in children, while Hangeshasin-to was reported to have anti-diarrheal effect in druginduced diarrhea. Two single-blind clinical trials involving a total of 273 subjects found no difference between acupuncture and sham acupuncture. $^{213,214}$

Statement 36: Traditional Chinese medicines including herbal 
and patent prescriptions could be helpful for some IBS patients, but the efficacies should be validated with high quality RCT.

Grade of evidence: moderate

Level of agreement: a. $76.2 \%$; b. 9.5\%; c. $9.5 \%$; d. $0.0 \%$; e. $0.0 \%$; f. $4.8 \%$

A meta-analysis of $14 \mathrm{RCT}$ s of Chinese herbal medicines, involving 1551 subjects with IBS-D, found efficacy for global IBS symptoms, abdominal pain and diarrhea, but recognized that there was high heterogeneity and study sample sizes were generally small. ${ }^{215}$ One formulation known as Shugan Jianpi Zhixie had 7 trials of 954 IBS-D patients. ${ }^{216}$ Another formulation known as Tongxie Yaofang had 23 publications involving 1972 IBS-D patients. ${ }^{217}$ A very recently published RCT had 1044 patients with Rome III criteria IBS randomized to 3 treatments for 4 weeks, and found that Tongxie Yaofang was significantly better than placebo for improving abdominal pain and stool parameters, but not better than pinaverium for abdominal pain. ${ }^{218}$

Statement 37: Psychotherapy is possibly useful in IBS, but data only supports its use in tertiary care patients.

\section{Grade of evidence: low}

Level of agreement: a. $90.5 \%$; b. $9.5 \%$; c. $0.0 \%$; d. $0.0 \%$; e. $0.0 \%$; f. $0.0 \%$

A meta-analysis of $41 \mathrm{RCTs}$ of psychotherapy for adults with IBS, found that none of the trials were at low risk of bias for every domain. ${ }^{219}$ The majority of studies were from USA, Sweden, and UK. On review of the demographic characteristics of study participants, it was acknowledged that the majority of patients were white and female. Asian experience with psychotherapy is limited to only one study each from Korea ${ }^{220}$ and from Japan. ${ }^{221}$ The Korean study employed cognitive behavioral therapy and recruited only female nursing students. ${ }^{220}$ This limits the generalizability of the outcome as the expectation is that these subjects were young and familiar with clinical science. The Japanese study employed autogenic training as a relaxation technique. ${ }^{221}$ The sample size was small (10 male and 11 female) and subjects were recruited from a psychosomatic department. Thus, the acceptance and understanding of this technique by a broader group of IBS subjects are unknown.

Another meta-analysis of $36 \mathrm{RCT}$ s involving a variety of psychotherapies (including cognitive behavioral therapy, relaxation therapy, hypnotherapy, dynamic psychotherapy and mindfulness) involving a total of 2189 patients found that overall IBS symptoms did not improve in 52\% compared with $76 \%$ receiving control in the form of symptom monitoring, physician's usual management, supportive therapy or placebo. ${ }^{186}$ There were serious issues regard- ing the validity of the findings as none of the trials were at low risk of bias, $22(61.0 \%)$ studies were based in tertiary care setting, 30 $(83.0 \%)$ studies were unblinded and concealment of allocation was not stated in 24 (67.0\%) studies. It remains unclear whether psychotherapy is effective for the treatment of IBS in primary care, with only 2 of the RCTs conducted entirely within this setting. ${ }^{222} \mathrm{~A}$ further concern was that 9 of the eligible studies originated from the same center, and when a subgroup analysis was conducted examining this issue there appeared to be a greater treatment effect in these 9 studies than in the 11 studies emanating from other centers.

A number of weaknesses common to several RCTs of psychological therapies were their failure to use the Rome criteria, absence of a power calculation, use of non-validated outcome measures, and inadequate blinding. ${ }^{222}$ Furthermore, the effect of psychotherapy on IBS symptoms in the long term remains unknown. ${ }^{219,222,223}$

\section{Conclusions}

Our consensus sought to represent current knowledge in a way that will be clinically useful to doctors treating IBS in Asia. The first and rate-limiting step in its management is to be able to make an early and confident diagnosis of IBS. Thus, it is important that physicians in Asia are able to recognize IBS based on the Asian experience, rather than parameters set by the West. In a landmark panAsian study, the pattern of symptom clusters in FGID patients was found to be quite different from the classification system proposed by the Rome committee. ${ }^{224} \mathrm{~A}$ greater emphasis was placed on mealrelated symptoms by Asian patients with IBS criteria. In fact, subsequent reports from Australia and from a Rome Foundation study group also found that there are important issues with the Rome IV criteria. ${ }^{225,226}$ Future research in Asia should test the Asian symptom clusters against the Rome-proposed symptom clusters. We should also test whether socio-cultural and environmental factors influence the greater overlap between IBS and upper GI symptoms in Asia, and whether this makes it more challenging to recognize IBS here.

Asian data substantiate the global research that now places IBS as a disorder of gut-brain interaction, recognizing the key role of the intestinal micro-environment. Previous emphasis on the psychological disturbance could have contributed to a lack of interest in IBS within the GI community in Asia. The emergence of more effective treatments with peripheral targets should encourage greater effort to recognize IBS in our patients. Furthermore, our rich heritage of traditional Asian treatments, together with emerging data on the potential of herbal medicines, earmarks this as an important field of exploration for future treatments. All patients with IBS should be 
evaluated comprehensively with a view to holistic management.

Financial support and conflicts of interest: Kok Ann Gwee reports grants and personal fees from Abbott Laboratories (speaking honorarium and education grant), Pisai (education grant), Janssen Pharmaceuticals (education grant), Menarini AsiaPacific (advisory board, speakers' bureau and consultancy), Biocodex (advisory board), Pfizer (advisory board), LF Asia (education grant), and Teva Pharmaceutical (speaking honorarium) during the conduct of the study; Sutep Gonlachanvit reports personal fees and non-financial support from Takeda, Thailand, personal fees from Abott, Thailand, personal fees, and non-financial support from Eisai, Thailand, outside the submitted work; Uday C Ghoshal has an Indian patent (application No. 201611031351; Indigenous radio-opaque markers for assessment of colonic transit time) pending and another Indian patent (application No. 201711040370; A double lumen tube assembly to prevent contamination by inhabitant microbes from proximal parts such as oropharynx) pending. Hiroto Miwa reports grants and personal fees (speaking honorarium) from Astellas and Mylan EPD during the conduct of the study; Justin Wu reports personal fees from Menarini outside the submitted work; Hidekazu Suzuki reports personal fees from Takeda, personal fees from Otsuka, personal fees from Astellas, personal fees from EA Pharma, personal fees from Daiichi-Sankyo, personal fees from Mylan EPD, personal fees from Astrazeneca, grants from Daiichi-Sankyo, outside the submitted work; Shin Fukudo reports the following activities outside the submitted work; personal fees from Dainippon Sumitomo Pharma, grants and personal fees from Abott Japan, personal fees from Scampo Pharma, grants from Ono Pharmaceutical, grants and personal fees from Astellas Pharmaceutical, personal fees from Sanwa Chemical Co. Ltd, personal fees from Zeria, personal fees from Glaxo-Smith-Kline, personal fees from Mochida Pharmaceutical, personal fees from Shionogi Pharmaceutical, grants and personal fees from AstraZeneca, grants from Smoking Research Foundation, grants and personal fees from Tsumuta Co. Ltd, personal fees and non-financial support from Miyarisan Pharmaceutical, grants from Kao Co. Ltd, and grants from Zespri Co. Ltd, and grants and personal fees from Kissei Pharmaceutical. Michio Hongo reports personal fees from Astellas, personal fees from Mylan EPD, personal fees from Kissei, during the conduct of the study, and personal fees from Sanwa Kagaku, personal fees from Mochida, outside the submitted work.

Author contributions: Participants were organized into 4 teams to review the evidence and develop statements comprising: symp- toms and epidemiology (Hiroto Miwa, Ching-Liang Lu, Minhu Chen, Hyojin Park, Andrew S B Chua, and Shin Fukudo), pathophysiology (Uday C Ghoshal, Xiaohua Hou, Myung-Gyu Choi, Sutep Gonlachanvit, and Michio Hongo), diagnosis and investigations (Justin Wu, Ari F Syam, Philip Abraham, Jose Sollano, and Young-Tae Bak), and lifestyle modifications and treatments (Kok Ann Gwee, Chi-Sen Chang, Hidekazu Suzuki, Oh Young Lee, and Xiucai Fang). All other faculty members contributed by reviewing and discussing the statements and supporting evidence, voting, reading, and approving the manuscript.

\section{References}

1. Gwee KA, Bak YT, Ghoshal UC, et al. Asian consensus on irritable bowel syndrome. J Gastroenterol Hepatol 2010;25:1189-1205.

2. Drossman DA, Hasler WL. Rome IV-functional GI disorders: disorders of gut-brain interaction. Gastroenterology 2016;150:1257-1261.

3. Murphy MK, Black NA, Lamping DL, et al. Consensus development methods, and their use in clinical guideline development. Health Technol Assess 1998;2:i-iv, 1-88.

4. Atkins D, Best D, Briss PA, et al. Grading quality of evidence and strength of recommendations. BMJ 2004;328:1490.

5. Manning AP, Thompson WG, Heaton KW, Morris AF. Towards positive diagnosis of the irritable bowel. Br Med J 1978;2:653-654.

6. Thompson WG. Gastrointestinal symptoms in the irritable bowel compared with peptic ulcer and inflammatory bowel disease. Gut 1984;25:1089-1092.

7. Lacy BE, Mearin F, Chang L, et al. Bowel disorders. Gastroenterology 2016;150:1393-1407.

8. Pimentel M, Talley NJ, Quigley EM, Hani A, Sharara A, Mahachai V. Report from the multinational irritable bowel syndrome initiative 2012. Gastroenterology 2013;144:e1-e5.

9. Bai T, Xia J, Jiang Y, et al. Comparison of the Rome IV and Rome III criteria for IBS diagnosis: a cross-sectional survey. J Gastroenterol Hepatol 2017;32:1018-1025.

10. Kanazawa M, Miwa H, Nakagawa A, Kosako M, Akiho H, Fukudo S Abdominal bloating is the most bothersome symptom in irritable bowel syndrome with constipation (IBS-C): a large population-based internet survey in Japan. Biopsychosoc Med 2016;10:19.

11. Rahman MM, Mahadeva S, Ghoshal UC. Epidemiological and clinical perspectives on irritable bowel syndrome in India, Bangladesh and Malaysia: a review. World J Gastroenterol 2017;23:6788-6801.

12. Ghoshal UC, Abraham P, Bhatia SJ, e al. Comparison of manning, Rome I, II, and III, and Asian diagnostic criteria: report of the multicentric indian irritable bowel syndrome (MIIBS) study. Indian J Gastroenterol 2013;32:369-375.

13. Pop LL, Mureşan IA, Dumitraşcu DL. How much bloating in the irritable bowel syndrome? Rom J Intern Med 2018;56:221-226.

14. Heaton KW, Radvan J, Cripps H, Mountford RA, Braddon FE, Hughes AO. Defecation frequency and timing, and stool form in the 
general population: a prospective study. Gut 1992;33:818-824.

15. Fang X, Lu S, Pan G. [An epidemiologic study of bowel habit in adult non-patient population in Beijing area]. Zhonghua Yi Xue Za Zhi 2001;81:1287-1290. [Chinese]

16. Adibi P, Behzad E, Pirzadeh S, Mohseni M. Bowel habit reference values and abnormalities in young Iranian healthy adults. Dig Dis Sci 2007;52:1810-1813.

17. Ghoshal UC, Abraham P, Bhatt C, et al. Epidemiological and clinical profile of irritable bowel syndrome in India: report of the Indian society of gastroenterology task fForce. Indian J Gastroenterol 2008;27:22-28.

18. Degen LP, Phillips SF. How well does stool form reflect colonic transit? Gut 1996;39:109-113.

19. Lewis SJ, Heaton KW. Stool form scale as a useful guide to intestinal transit time. Scand J Gastroenterol 1997;32:920-924.

20. Heaton KW, O'Donnell LJ. An office guide to whole-gut transit time. Patients' recollection of their stool form. J Clin Gastroenterol 1994;19:2830.

21. Saad RJ, Rao SS, Koch KL, et al. Do stool form and frequency correlate with whole-gut and colonic transit? Results from a multicenter study in constipated individuals and healthy controls. Am J Gastroenterol 2010;105:403-411.

22. Amarenco G. [Bristol stool chart: prospective and monocentric study of "stools introspection" in healthy subjects]. Prog Urol 2014; 24:708-13. [French]

23. Kellow JE, Phillips SF, Miller LJ, Zinsmeister AR. Dysmotility of the small intestine in irritable bowel syndrome. Gut 1988;29:1236-1243.

24. Sullivan MA, Cohen S, Snape WJ Jr. Colonic myoelectrical activity in irritable-bowel syndrome. Effect of eating and anticholinergics. N Engl J Med 1978;298:878-883.

25. Evans PR, Bennett EJ, Bak YT, Tennant CC, Kellow JE. Jejunal sensorimotor dysfunction in irritable bowel syndrome: clinical and psychosocial features. Gastroenterology 1996;110:393-404.

26. Chang L, Lee OY, Naliboff B, Schmulson M, Mayer EA. Sensation of bloating and visible abdominal distension in patients with irritable bowel syndrome. Am J Gastroenterol 2001;96:3341-3347.

27. Ragnarsson G, Bodemar G. Pain is temporally related to eating but not to defaecation in the irritable bowel syndrome (IBS). Patients' description of diarrhea, constipation and symptom variation during a prospective 6-week study. Eur J Gastroenterol Hepatol 1998;10:415-421.

28. Gwee KA, Lu CL, Ghoshal UC. Epidemiology of irritable bowel syndrome in Asia: something old, something new, something borrowed. J Gastroenterol Hepatol 2009;24:1601-1607.

29. Siah KTH, Gong X, Yang XJ, et al. Rome foundation-asian working team report: asian functional gastrointestinal disorder symptom clusters. Gut 2018;67:1071-1077.

30. Lu CL, Lang HC, Chang FY, et al. Prevalence and health/social impacts of functional dyspepsia in Taiwan: a study based on the Rome criteria questionnaire survey assisted by endoscopic exclusion among a physical check-up population. Scand J Gastroenterol 2005;40:402-411.

31. Lu CL, Chen CY, Lang HC, et al. Current patterns of irritable bowel syndrome in Taiwan: the Rome II questionnaire on a Chinese population. Aliment Pharmacol Ther 2003;18:1159-1169.
32. Arsiè E, Coletta M, Cesana BM, Basilisco G. Symptom-association probability between meal ingestion and abdominal pain in patients with irritable bowel syndrome. Does somatization play a role? Neurogastroenterol Motil 2015;27:416-422.

33. Lovell RM, Ford AC. Effect of gender on prevalence of irritable bowel syndrome in the community: systematic review and meta-analysis. Am J Gastroenterol 2012;107:991-1000.

34. Sperber AD, Dumitrascu D, Fukudo S, et al. The global prevalence of IBS in adults remains elusive due to the heterogeneity of studies: a Rome foundation working team literature review. Gut 2017;66:1075-1082.

35. Quigley EM, Bytzer P, Jones R, Mearin F. Irritable bowel syndrome: the burden and unmet needs in Europe. Dig Liver Dis 2006;38:717-723.

36. Makharia GK, Verma AK, Amarchand R, et al. Prevalence of irritable bowel syndrome: a community based study from northern India. J Neurogastroenterol Motil 2011;17:82-87.

37. Lee YY, Waid A, Tan HJ, Chua AS, Whitehead WE. Rome III survey of irritable bowel syndrome among ethnic Malays. World J Gastroenterol 2012;18:6475-6480; discussion 6479.

38. Satake R, Sugawara N, Sato K, et al. Prevalence and predictive factors of irritable bowel syndrome in a community-dwelling population in Japan. Intern Med 2015;54:3105-3112.

39. Masud MA, Hasan M, Khan AK. Irritable bowel syndrome in a rural community in Bangladesh: prevalence, symptoms pattern, and health care seeking behavior. Am J Gastroenterol 2001;96:1547-1552.

40. Naeem SS, Siddiqui EU, Kazi AN, Memon AA, Khan ST, Ahmed B. Prevalence and factors associated with irritable bowel syndrome among medical students of Karachi, Pakistan: a cross-sectional study. BMC Res Notes 2012;5:255

41. Shah SS, Bhatia SJ, Mistry FP. Epidemiology of dyspepsia in the general population in Mumbai. Indian J Gastroenterol 2001;20:103-106.

42. Si JM, Wang LJ, Chen SJ, Sun LM, Dai N. Irritable bowel syndrome consulters in Zhejiang province: the symptoms pattern, predominant bowel habit subgroups and quality of life. World J Gastroenterol 2004;10:1059-1064.

43. Wang A, Liao X, Xiong L, et al. The clinical overlap between functional dyspepsia and irritable bowel syndrome based on Rome III criteria. BMC Gastroenterol 2008;8:43.

44. Lee SY, Lee KJ, Kim SJ, Cho SW. Prevalence and risk factors for overlaps between gastroesophageal reflux disease, dyspepsia, and irritable bowel syndrome: a population-based study. Digestion 2009;79:196-201.

45. Kang JY, Tay HH, Guan R. Chronic upper abdominal pain: site and radiation in various structural and functional disorders and the effect of various foods. Gut 1992;33:743-748.

46. Gwee KA, Wee S, Wong ML, Png DJ. The prevalence, symptom characteristics, and impact of irritable bowel syndrome in an asian urban community. Am J Gastroenterol 2004;99:924-931.

47. Ghoshal UC, Singh R. Frequency and risk factors of functional gastrointestinal disorders in a rural Indian population. J Gastroenterol Hepatol 2017;32:378-387.

48. Perveen I, Rahman MM, Saha M, Rahman MM, Hasan MQ. Prevalence of irritable bowel syndrome and functional dyspepsia, overlapping symptoms, and associated factors in a general population of Bangladesh. 
Indian J Gastroenterol 2014;33:265-273.

49. Whitehead WE, Crowell MD, Robinson JC, Heller BR, Schuster MM. Effects of stressful life events on bowel symptoms: subjects with irritable bowel syndrome compared with subjects without bowel dysfunction. Gut 1992;33:825-830.

50. Fukudo S, Suzuki J. Colonic motility, autonomic function, and gastrointestinal hormones under psychological stress on irritable bowel syndrome. Tohoku J Exp Med 1987;151:373-385.

51. Tillisch K, Mayer EA, Labus JS. Quantitative meta-analysis identifies brain regions activated during rectal distension in irritable bowel syndrome. Gastroenterology 2011;140:91-100.

52. Aizawa E, Sato Y, Kochiyama T, et al. Altered cognitive function of prefrontal cortex during error feedback in patients with irritable bowel syndrome, based on FMRI and dynamic causal modeling. Gastroenterology 2012;143:1188-1198.

53. Enck P, Aziz Q, Barbara G, et al. Irritable bowel syndrome. Nat Rev Dis Primers 2016;2:16014.

54. Qin HY, Cheng CW, Tang XD, Bian ZX. Impact of psychological stress on irritable bowel syndrome. World J Gastroenterol 2014;20:1412614131.

55. Moloney RD, Johnson AC, O'Mahony SM, et al. Stress and the microbiota-gut-brain zxis in visceral pain: relevance to irritable bowel syndrome. CNS Neurosci Ther 2016;22:102-117.

56. Spiller R, Garsed K. Postinfectious irritable bowel syndrome. Gastroenterology 2009;136:1979-1988.

57. Spiller R, Aziz Q, Creed F, et al. Guidelines on the irritable bowel syndrome: mechanisms and practical management. Gut 2007;56:17701798.

58. Koloski NA, Jones M, Kalantar J, Weltman M, Zaguirre J, Talley NJ. The brain--gut pathway in functional gastrointestinal disorders is bidirectional: a 12-year prospective population-based study. Gut 2012;61:12841290

59. Koloski NA, Jones M, Talley NJ. Evidence that independent gut-tobrain and brain-to-gut pathways operate in the irritable bowel syndrome and functional dyspepsia: a 1-year population-based prospective study. Aliment Pharmacol Ther 2016;44:592-600.

60. Barbara G, Feinle-Bisset C, Ghoshal UC, et al. The intestinal microenvironment and functional gastrointestinal disorders. Gastroenterology 2016;150:1305-1318, e8.

61. Shukla R, Ghoshal U, Dhole TN, Ghoshal UC. Fecal microbiota in patients with irritable bowel syndrome compared with healthy controls using real-time polymerase chain reaction: an evidence of dysbiosis. Dig Dis Sci 2015;60:2953-2962.

62. Zhuang X, Xiong L, Li L, Li M, Chen M. Alterations of gut microbiota in patients with irritable bowel syndrome: a systematic review and meta-analysis. J Gastroenterol Hepatol 2017;32:28-38.

63. Chung CS, Chang PF, Liao CH, et al. Differences of microbiota in small bowel and faeces between irritable bowel syndrome patients and healthy subjects. Scand J Gastroenterol 2016;51:410-419.

64. Ghoshal UC, Srivastava D, Ghoshal U, Misra A. Breath tests in the diagnosis of small intestinal bacterial overgrowth in patients with irritable bowel syndrome in comparison with quantitative upper gut aspirate cul- ture. Eur J Gastroenterol Hepatol 2014;26:753-760.

65. Pimentel M, Lembo A, Chey WD, et al. Rifaximin therapy for patients with irritable bowel syndrome without constipation. N Engl J Med 2011;364:22-32.

66. Ghoshal UC, Srivastava D, Misra A, Ghoshal U. A proof-of-concept study showing antibiotics to be more effective in irritable bowel syndrome with than without small-intestinal bacterial overgrowth: a randomized, double-blind, placebo-controlled trial. Eur J Gastroenterol Hepatol 2016;28:281-289.

67. Ghoshal UC, Srivastava D. Irritable bowel syndrome and small intestinal bacterial overgrowth: meaningful association or unnecessary hype. World J Gastroenterol 2014;20:2482-2491.

68. Ghoshal UC, Srivastava D, Misra A. A randomized double-blind placebo-controlled trial showing rifaximin to improve constipation by reducing methane production and accelerating colon transit: a pilot study. Indian J Gastroenterol 2018;37:416-423.

69. Shah A, Morrison M, Holtmann G. A novel treatment for patients with constipation: dawn of a new age for translational microbiome research? Indian J Gastroenterol 2018:37:388-391.

70. Gwee KA, Collins SM, Read NW, et al. Increased rectal mucosal expression of interleukin 1beta in recently acquired post-infectious irritable bowel syndrome. Gut 2003;52:523-526.

71. Spiller RC, Jenkins D, Thornley JP, et al, Increased rectal mucosal enteroendocrine cells, $\mathrm{T}$ lymphocytes, and increased gut permeability following acute Campylobacter enteritis and in post-dysenteric irritable bowel syndrome. Gut 2000;47:804-811.

72. Dunlop SP, Hebden J, Campbell E, et al. Abnormal intestinal permeability in subgroups of diarrhea-predominant irritable bowel syndromes. Am J Gastroenterol 2006;101:1288-1294.

73. Chadwick VS, Chen W, Shu D, et al. Activation of the mucosal immune system in irritable bowel syndrome. Gastroenterology 2002;122:17781783.

74. Ohman L, Simrén M. Pathogenesis of IBS: role of inflammation, immunity and neuroimmune interactions. Nat Rev Gastroenterol Hepatol 2010;7:163-173.

75. Wang LH, Fang XC, Pan GZ. Bacillary dysentery as a causative factor of irritable bowel syndrome and its pathogenesis. Gut 2004;53:10961101

76. Srivastava D, Ghoshal U, Mittal RD, Ghoshal UC. Associations between IL-1RA polymorphisms and small intestinal bacterial overgrowth among patients with irritable bowel syndrome from India. Neurogastroenterol Motil 2014;26:1408-1416.

77. Shukla R, Ghoshal U, Ranjan P, Ghoshal UC. Expression of toll-like receptors, pro-, and anti-inflammatory cytokines in relation to gut microbiota in irritable bowel syndrome: the evidence for its micro-organic basis. J Neurogastroenterol Motil 2018;24:628-642.

78. Chu H, Fox M, Zheng X, et al. Small intestinal bacterial overgrowth in patients with irritable bowel syndrome: clinical characteristics, psychological factors, and peripheral cytokines. Gastroenterol Res Pract 2016;2016:3230859.

79. Xu XJ, Zhang YL, Liu L, Pan L, Yao SK. Increased expression of nerve growth factor correlates with visceral hypersensitivity and impaired gut 
barrier function in diarrhoea-predominant irritable bowel syndrome: a preliminary explorative study. Aliment Pharmacol Ther 2017;45:100114.

80. Chaudhary NA, Truelove SC. The irritable colon syndrome. A study of the clinical features, predisposing causes, and prognosis in 130 cases. Q J Med 1962;31:307-322.

81. Gwee KA, Graham JC, McKendrick MW, et al. Psychometric scores and persistence of irritable bowel after infectious diarrhoea. Lancet 1996;347:150-153.

82. Ji S, Park H, Lee D, Song YK, Choi JP, Lee SI. Post-infectious irritable bowel syndrome in patients with Shigella infection. J Gastroenterol Hepatol 2005;20:381-386.

83. Kim HS, Kim MS, Ji SW, Park H. [The development of irritable bowel syndrome after Shigella infection: 3 year follow-up study]. Korean J Gastroenterol 2006;47:300-305. [Korean]

84. Rahman MM, Ghoshal UC, Sultana S, et al.. Long-term gastrointestinal consequences are frequent following sporadic acute infectious diarrhea in a tropical country: a prospective cohort study. Am J Gastroenterol 2018;113:1363-1375.

85. Ghoshal UC, Gwee KA. Post-infectious IBS, tropical sprue and small intestinal bacterial overgrowth: the missing link. Nat Rev Gastroenterol Hepatol 2017;14:435-441.

86. Barbara G, Grover M, Bercik P, et al. Rome foundation working team report on post-infection irritable bowel syndrome. Gastroenterology 2019;156:46-58, e7.

87. Mertz H, Naliboff B, Munakata J, Niazi N, Mayer EA. Altered rectal perception is a biological marker of patients with irritable bowel syndrome. Gastroenterology 1995;109:40-52.

88. Gupta D, Ghoshal UC, Misra A, Misra A, Choudhuri G, Singh K. Lactose intolerance in patients with irritable bowel syndrome from northern India: a case-control study. J Gastroenterol Hepatol 2007;22:22612265 .

89. Trimble KC, Farouk R, Pryde A, Douglas S, Heading RC. Heightened visceral sensation in functional gastrointestinal disease is not site-specific. Evidence for a generalized disorder of gut sensitivity. Dig Dis Sci 1995;40:1607-1613.

90. Zhu Y, Zheng X, Cong Y, et al. Bloating and distention in irritable bowel syndrome: the role of gas production and visceral sensation after lactose ingestion in a population with lactase deficiency. Am J Gastroenterol 2013;108:1516-1525.

91. Zuo XL, Li YQ, Shi L, et al. Visceral hypersensitivity following cold water intake in subjects with irritable bowel syndrome. J Gastroenterol 2006;41:311-317.

92. Kang JY, Gwee KA, Yap I. The colonic air insufflation test indicates a colonic cause of abdominal pain. An aid in the management of irritable bowel syndrome. J Clin Gastroenterol 1994;18:19-22.

93. Cremon C, Carini G, Wang B, et al. Intestinal serotonin release, sensory neuron activation, and abdominal pain in irritable bowel syndrome. Am J Gastroenterol 2011;106:1290-1298.

94. Zhang ZF, Duan ZJ, Wang LX, Yang D, Zhao G, Zhang L. The serotonin transporter gene polymorphism (5-HTTLPR) and irritable bowel syndrome: a meta-analysis of 25 studies. BMC Gastroenterol
2014;14:23.

95. Dunlop SP, Coleman NS, Blackshaw E, et al. Abnormalities of 5-hydroxytryptamine metabolism in irritable bowel syndrome. Clin Gastroenterol Hepatol 2005;3:349-357.

96. Gonlachanvit S, Fongkam P, Wittayalertpanya S, Kullavanijaya P. Red chili induces rectal hypersensitivity in healthy humans: possible role of 5 HT-3 receptors on capsaicin-sensitive visceral nociceptive pathways. Aliment Pharmacol Ther 2007;26:617-625.

97. El-Salhy M, Patcharatrakul T, Hatlebakk JG, Hausken T, Gilja OH, Gonlachanvit S. Chromogranin A cell density in the large intestine of Asian and European patients with irritable bowel syndrome. Scand J Gastroenterol 2017;52:691-697.

98. Jeong JB, Yang YM, Jeon WJ, et al. Postprandial colonic motor activity in patients with irritable bowel syndrome. Kor J Neurogastroenterol Motil 2000;6:20-30.

99. Shah SK, Abraham P, Mistry FP. Effect of cold pressor test and a highchilli diet on rectosigmoid motility in irritable bowel syndrome. Indian J Gastroenterol 2000;19:161-164.

100. Gonlachanvit S, Mahayosnond A, Kullavanijaya P. Effects of chili on postprandial gastrointestinal symptoms in diarrhoea predominant irritable bowel syndrome: evidence for capsaicin-sensitive visceral nociception hypersensitivity. Neurogastroenterol Motil 2009;21:23-32.

101.Sagami Y, Shimada Y, Tayama J, et al. Effect of a corticotropin releasing hormone receptor antagonist on colonic sensory and motor function in patients with irritable bowel syndrome. Gut 2004;53:958-964.

102. Fukudo S. Role of corticotropin-releasing hormone in irritable bowel syndrome and intestinal inflammation. J Gastroenterol 2007;42(suppl 17):48-51.

103.Shin A, Camilleri M, Vijayvargiya P, et al. Bowel functions, fecal unconjugated primary and secondary bile acids, and colonic transit in patients with irritable bowel syndrome. Clin Gastroenterol Hepatol 2013;11:1270-1275, e1.

104. Camilleri M, McKinzie S, Busciglio I, et al. Prospective study of motor, sensory, psychologic, and autonomic functions in patients with irritable bowel syndrome. Clin Gastroenterol Hepatol 2008;6:772-781.

105. Tandon RK, Prasad N, Gupta MC, Tandon BN. Stool weights and transit time in North Indians. J Assoc Physicians India 1976;24:807-810.

106. Chan YK, Kwan AC, Yuen H, et al. Normal colon transit time in healthy Chinese adults in Hong Kong. J Gastroenterol Hepatol 2004;19:12701275.

107.Hamaguchi T, Kano M, Rikimaru H, et al. Brain activity during distention of the descending colon in humans. Neurogastroenterol Motil 2004;16:299-309.

108. Yuan YZ, Tao RJ, Xu B, et al. Functional brain imaging in irritable bowel syndrome with rectal balloon-distention by using fMRI. World J Gastroenterol 2003;9:1356-1360.

109. Song GH, Venkatraman V, Ho KY, Chee MW, Yeoh KG, Wilder-Smith $\mathrm{CH}$. Cortical effects of anticipation and endogenous modulation of visceral pain assessed by functional brain MRI in irritable bowel syndrome patients and healthy controls. Pain 2006;126:79-90.

110. Guleria A, Karyampudi A, Singh R, et al. Mapping of brain activations to rectal balloon distension stimuli in male patients with irritable bowel 
syndrome using functional magnetic resonance imaging. J Neurogastroenterol Motil 2017;23:415-427.

111. Van Oudenhove L, Vandenberghe J, Demyttenaere K, Tack J. Psychosocial factors, psychiatric illness and functional gastrointestinal disorders: a historical perspective. Digestion 2010;82:201-210.

112. Cho KR, Lee OY, Yoon DH, et al. The influence of depression on gastrointestinal symptoms in women. Kor J Neurogastroenterol Motil 2007;13:146-151.

113. Shinozaki M, Fukudo S, Hongo M, et al. High prevalence of irritable bowel syndrome in medical outpatients in Japan. J Clin Gastroenterol 2008;42:1010-1016.

114. Hu WH, Wong WM, Lam CL, et al. Anxiety but not depression determines health care-seeking behaviour in Chinese patients with dyspepsia and irritable bowel syndrome: a population-based study. Aliment Pharmacol Ther 2002;16:2081-2088.

115. Husain N, Chaudhry IB, Jafri F, Niaz SK, Tomenson B, Creed F. A population-based study of irritable bowel syndrome in a non-Western population. Neurogastroenterol Motil 2008;20:1022-1029.

116. Kanazawa M, Endo Y, Whitehead WE, Kano M, Hongo M, Fukudo S. Patients and nonconsulters with irritable bowel syndrome reporting a parental history of bowel problems have more impaired psychological distress. Dig Dis Sci 2004;49:1046-1053.

117. Jun DW, Lee OY, Jo GL, et al. The comparison of irritable bowel syndrome between consulters and non-consulters. Kor J Neurogastroenterol Motil 2018;11:50-57.

118. Ghoshal UC, Singh R. Pathogenesis of irritable bowel syndrome: is it really in the gene? J Neurogastroenterol Motil 2014;20:284-286.

119. Ghoshal UC. Pros and cons while looking through an asian window on the rome IV criteria for irritable bowel syndrome: pros. J Neurogastroenterol Motil 2017;23:334-340.

120. Jaruvongvanich V, Patcharatrakul T, Gonlachanvit S. Prediction of delayed colonic transit using bristol stool form and stool frequency in eastern constipated patients: a difference from the west. J Neurogastroenterol Motil 2017;23:561-568.

121. Blake MR, Raker JM, Whelan K. Validity and reliability of the bristol stool form scale in healthy adults and patients with diarrhoea-predominant irritable bowel syndrome. Aliment Pharmacol Ther 2016;44:693-703.

122. Shim L, Talley NJ, Boyce P, Tennant C, Jones M, Kellow JE. Stool characteristics and colonic transit in irritable bowel syndrome: evaluation at two time points. Scand J Gastroenterol 2013;48:295-301.

123. Ford AC, Bercik P, Morgan DG, Bolino C, Pintos-Sanchez MI, Moayyedi P. Validation of the Rome III criteria for the diagnosis of irritable bowel syndrome in secondary care. Gastroenterology 2013;145:12621270 , e1.

124. Patel P, Bercik P, Morgan DG, et al. Prevalence of organic disease at colonoscopy in patients with symptoms compatible with irritable bowel syndrome: cross-sectional survey. Scand J Gastroenterol 2015;50:816823.

125. Chey WD, Nojkov B, Rubenstein JH, Dobhan RR, Greenson JK, Cash $\mathrm{BD}$. The yield of colonoscopy in patients with non-constipated irritable bowel syndrome: results from a prospective, controlled US trial. Am J Gastroenterol 2010;105:859-865.
126.Emmanuel A, Landis D, Peucker M, Hungin AP. Faecal biomarker patterns in patients with symptoms of irritable bowel syndrome. Frontline Gastroenterol 2016;7:275-282.

127. Rao VL, Micic D, Kim KE. Primary care evaluation and management of gastroenterologic issues in women. Obstet Gynecol Clin North Am 2016;43:347-366.

128. Rey Díaz-Rubio E, Mascort Roca JJ, Peña Forcada E, Cañones Garzón P, Tenias Burillo JM, Júdez Gutiérrez FJ. Management of the clinical issue of constipation with abdominal complaints in adults. A national survey of Primary Care physicians and gastroenterologists. Rev Esp Enferm Dig 2016;108:323-331.

129. Corsetti M, Whorwell PJ. Managing irritable bowel syndrome in primary care. Practitioner 2015;259:21-24, 2-3.

130. Menees SB, Powell C, Kurlander J, Goel A, Chey WD. A meta-analysis of the utility of C-reactive protein, erythrocyte sedimentation rate, fecal calprotectin, and fecal lactoferrin to exclude inflammatory bowel disease in adults with IBS. Am J Gastroenterol 2015;110:444-454.

131.Vasquez-Rios G, Machicado JD, Terashima A, Marcos LA. Irritable bowel syndrome and intestinal parasites: a view from South America. Rev Gastroenterol Peru 2016;36:153-158.

132.Sung JJ, Ng SC, Chan FK, et al. An updated asia pacific consensus recommendations on colorectal cancer screening. Gut 2015;64:121-132.

133. Sharma H, Verma AK, Das P, Dattagupta S, Ahuja V, Makharia GK. Prevalence of celiac disease in Indian patients with irritable bowel syndrome and uninvestigated dyspepsia. J Dig Dis 2015;16:443-448.

134. Chowdhury MK, Chakraborty R, Gope S, et al. Celiac disease in patients fulfilling the Rome III criteria for irritable bowel syndrome attending gastroenterology department of a tertiary care hospital in bangladesh. Mymensingh Med J 2016;25:102-108.

135. Wang H, Zhou G, Luo L, et al. Serological screening for celiac disease in adult Chinese patients with diarrhea predominant irritable bowel syndrome. Medicine (Baltimore) 2015;94:e1779.

136. Ghoshal UC, Verma A, Misra A. Frequency, spectrum, and factors associated with fecal evacuation disorders among patients with chronic constipation referred to a tertiary care center in northern India. Indian J Gastroenterol 2016;35:83-90.

137.Patcharatrakul T, Gonlachanvit S. Outcome of biofeedback therapy in dyssynergic defecation patients with and without irritable bowel syndrome. J Clin Gastroenterol 2011;45:593-598.

138. Ghoshal UC. Chronic constipation in Rome IV era: the Indian perspective. Indian J Gastroenterol 2017;36:163-173.

139.Lu W, Gwee KA, Siah KT, Kang JY, Lee R, Ngan CC. Prevalence of anti-deamidated gliadin peptide antibodies in asian patients with irritable bowel syndrome. J Neurogastroenterol Motil 2014;20:236-241.

140. Shahbazkhani B, Sadeghi A, Malekzadeh R, et al. Non-celiac gluten sensitivity has narrowed the spectrum of irritable bowel syndrome: a doubleblind randomized placebo-controlled trial. Nutrients 2015;7:4542-4554.

141.Makharia A, Catassi C, Makharia GK. The overlap between irritable bowel syndrome and non-celiac gluten sensitivity: a clinical dilemma. Nutrients 2015;7:10417-10426.

142. Choi MG, Jung HK. Health related quality of life in functional gastrointestinal disorders in Asia. J Neurogastroenterol Motil 2011;17:245-251. 
143. Wang YT, Lim HY, Tai D, et al. The impact of irritable bowel syndrome on health-related quality of life: a Singapore perspective. BMC Gastroenterol 2012;12:104

144.Park JM, Choi MG, Kim YS, et al. Quality of life of patients with irritable bowel syndrome in Korea. Qual Life Res 2009;18:435-446.

145. Gwee KA, Ghoshal UC, Chen M. Irritable bowel syndrome in asia: pathogenesis, natural history, epidemiology, and management. J Gastroenterol Hepatol 2018;33:99-110.

146. Ong DK, Mitchell SB, Barrett JS, et al. Manipulation of dietary short chain carbohydrates alters the pattern of gas production and genesis of symptoms in irritable bowel syndrome. J Gastroenterol Hepatol 2010;25:1366-1373.

147. Halmos EP, Power VA, Shepherd SJ, Gibson PR, Muir JG. A diet low in FODMAPs reduces symptoms of irritable bowel syndrome. Gastroenterology 2014;146:67-75, e5.

148. Iacovou M, Tan V, Muir JG, Gibson PR. The low FODMAP diet and its application in east and southeast asia. J Neurogastroenterol Motil 2015;21:459-470.

149. Hewawasam SP, Iacovou M, Muir JG, Gibson PR. Dietary practices and FODMAPs in south asia: applicability of the low FODMAP diet to patients with irritable bowel syndrome. J Gastroenterol Hepatol 2018;33:365-374.

150. Yang J, Deng Y, Chu H, et al. Prevalence and presentation of lactose intolerance and effects on dairy product intake in healthy subjects and patients with irritable bowel syndrome. Clin Gastroenterol Hepatol 2013;11:262-268.

151. Ghoshal UC, Kumar S, Misra A, Mittal B. Lactose malabsorption diagnosed by $50 \mathrm{~g}$ dose is inferior to assess clinical intolerance and to predict response to milk withdrawal than 25 -g dose in an endemic area. J Gastroenterol Hepatol 2013;28:1462-1468.

152. Ford AC, Talley NJ, Spiegel BM, et al. Effect of fibre, antispasmodics, and peppermint oil in the treatment of irritable bowel syndrome: systematic review and meta-analysis. BMJ 2008;337:a2313.

153. Ruepert L, Quartero AO, de Wit NJ, van der Heijden GJ, Rubin G, Muris JW. Bulking agents, antispasmodics and antidepressants for the treatment of irritable bowel syndrome. Cochrane Database Syst Rev 2011:CD003460.

154.Zheng L, Lai Y, Lu W, et al. Pinaverium reduces symptoms of irritable bowel syndrome in a multicenter, randomized, controlled trial. Clin Gastroenterol Hepatol 2015;13:1285-1292, e1.

155.Lu CL, Chen CY, Chang FY, et al. Effect of a calcium channel blocker and antispasmodic in diarrhoea-predominant irritable bowel syndrome. J Gastroenterol Hepatol 2000;15:925-930.

156. Chang FY, Lu CL, Luo JC, Chen TS, Chen MJ, Chang HJ. The evaluation of otilonium bromide treatment in asian patients with irritable bowel syndrome. J Neurogastroenterol Motil 2011;17:402-410.

157.Liu JH, Chen GH, Yeh HZ, Huang CK, Poon SK. Enteric-coated peppermint-oil capsules in the treatment of irritable bowel syndrome: a prospective, randomized trial. J Gastroenterol 1997;32:765-768.

158. Cann PA, Read NW, Holdsworth CD, Barends D. Role of loperamide and placebo in management of irritable bowel syndrome (IBS). Dig Dis Sci 1984;29:239-247.
159.Lavö B, Stenstam M, Nielsen AL. Loperamide in treatment of irritable bowel syndrome--a double-blind placebo controlled study. Scand J Gastroenterol Suppl 1987;130:77-80.

160.Efskind PS, Bernklev T, Vatn MH. A double-blind placebo-controlled trial with loperamide in irritable bowel syndrome. Scand J Gastroenterol 1996;31:463-468.

161. Chang FY, Lu CL, Chen CY, Luo JC. Efficacy of dioctahedral smectite in treating patients of diarrhea-predominant irritable bowel syndrome. J Gastroenterol Hepatol 2007;22:2266-2272.

162. Ducrotte P, Dapoigny M, Bonaz B, Siproudhis L. Symptomatic efficacy of beidellitic montmorillonite in irritable bowel syndrome: a randomized, controlled trial. Aliment Pharmacol Ther 2005;21:435-444.

163. Gershon MD. Review article: serotonin receptors and transporters -roles in normal and abnormal gastrointestinal motility. Aliment Pharmacol Ther 2004;20(suppl 7):3-14.

164.Goldberg PA, Kamm MA, Setti-Carraro P, van der Sijp JR, Roth C. Modification of visceral sensitivity and pain in irritable bowel syndrome by 5-HT3 antagonism (ondansetron). Digestion 1996;57:478-483.

165. Houghton LA, Foster JM, Whorwell PJ. Alosetron, a 5-HT 3 receptor antagonist, delays colonic transit in patients with irritable bowel syndrome and healthy volunteers. Aliment Pharmacol Ther 2000;14:775-782.

166. Matsueda K, Harasawa S, Hongo M, Hiwatashi N, Sasaki D. A phase II trial of the novel serotonin type 3 receptor antagonist ramosetron in Japanese male and female patients with diarrhea-predominant irritable bowel syndrome. Digestion 2008;77:225-235.

167. Matsueda K, Harasawa S, Hongo M, Hiwatashi N, Sasaki D. A randomized, double-blind, placebo-controlled clinical trial of the effectiveness of the novel serotonin type 3 receptor antagonist ramosetron in both male and female Japanese patients with diarrhea-predominant irritable bowel syndrome. Scand J Gastroenterol 2008;43:1202-1211.

168. Fukudo S, Kinoshita Y, Okumura T, et al. Ramosetron reduces symptoms of irritable bowel syndrome with diarrhea and improves quality of life in women. Gastroenterology 2016;150:358-366.

169. Ford AC, Moayyedi P, Lacy BE, et al. American college of gastroenterology monograph on the management of irritable bowel syndrome and chronic idiopathic constipation. Am J Gastroenterol 2014;109(suppl 1):S2-S26.

170. Garsed K, Chernova J, Hastings M, Lam C, Marciani L, Singh G, Henry A, Hall I, Whorwell P, Spiller R. A randomised trial of ondansetron for the treatment of irritable bowel syndrome with diarrhoea. Gut 2014; 63:1617-1625.

171. Kellow J, Lee OY, Chang FY, et al. An asia-pacific, double blind, placebo controlled, randomised study to evaluate the efficacy, safety, and tolerability of tegaserod in patients with irritable bowel syndrome. Gut 2003;52:671-676.

172. Fried M, Johanson JF, Gwee KA, Wagner A, Pecher E, Rueegg P. Efficacy of tegaserod in chronic constipation in men. Am J Gastroenterol 2007;102:362-370.

173. Harish K, Hazeena K, Thomas V, Kumar S, Jose T, Narayanan P. Effect of tegaserod on colonic transit time in male patients with constipationpredominant irritable bowel syndrome. J Gastroenterol Hepatol 2007;22:1183-1189. 
174. Tack J, Camilleri M, Chang L, et al. Systematic review: cardiovascular safety profile of 5- $\mathrm{HT}_{4}$ agonists developed for gastrointestinal disorders. Aliment Pharmacol Ther 2012;35:745-767.

175. Jadav AM, McMullin CM, Smith J, Chapple K, Brown SR. The association between prucalopride efficacy and constipation type. Tech Coloproctol 2013;17:555-559.

176. Tack J, Stanghellini V, Dubois D, Joseph A, Vandeplassche L, Kerstens R. Effect of prucalopride on symptoms of chronic constipation. Neurogastroenterol Motil 2014;26:21-27.

177. Leelakusolvong S, Ke M, Zou D, et al. Factors predictive of treatmentemergent adverse events of prucalopride: an integrated analysis of four randomized, double-blind, placebo-controlled trials. Gut Liver 2015;9:208-213.

178. Yiannakou Y, Piessevaux H, Bouchoucha M, et al. A randomized, double-blind, placebo-controlled, phase 3 trial to evaluate the efficacy, safety, and tolerability of prucalopride in men with chronic constipation. Am J Gastroenterol 2015;110:741-748.

179. Ke M, Zou D, Yuan Y, et al. Prucalopride in the treatment of chronic constipation in patients from the asia-pacific region: a randomized, double-blind, placebo-controlled study. Neurogastroenterol Motil 2012;24:999-e541.

180. Ford AC, Quigley EM, Lacy BE, et al. Efficacy of prebiotics, probiotics, and synbiotics in irritable bowel syndrome and chronic idiopathic constipation: systematic review and meta-analysis. Am J Gastroenterol 2014;109:1547-1561.

181. Horvath A, Dziechciarz P, Szajewska H. Meta-analysis: Lactobacillus rhamnosus GG for abdominal pain-related functional gastrointestinal disorders in childhood. Aliment Pharmacol Ther 2011;33:1302-1310.

182. Pedersen N, Andersen NN, Végh Z, Ehealth: low FODMAP diet vs Lactobacillus rhamnosus GG in irritable bowel syndrome. World J Gastroenterol 2014;20:16215-16226.

183. O'Mahony L, McCarthy J, Kelly P, et al. Lactobacillus and bifidobacterium in irritable bowel syndrome: symptom responses and relationship to cytokine profiles. Gastroenterology 2005;128:541-551.

184. Whorwell PJ, Altringer L, Morel J, et al. Efficacy of an encapsulated probiotic Bifidobacterium infantis 35624 in women with irritable bowel syndrome. Am J Gastroenterol 2006;101:1581-1590.

185. Gwee KA, Lee WW, Ling KL, et al. Consensus and contentious statements on the use of probiotics in clinical practice: a south east asian gastro-neuro motility association working team report. J Gastroenterol Hepatol 2018;33:1707-1716.

186. Ford AC, Quigley EM, Lacy BE, et al. Effect of antidepressants and psychological therapies, including hypnotherapy, in irritable bowel syndrome: systematic review and meta-analysis. Am J Gastroenterol 2014;109:1350-1365

187. Vahedi H, Merat S, Momtahen S, et al. Clinical trial: the effect of amitriptyline in patients with diarrhoea-predominant irritable bowel syndrome. Aliment Pharmacol Ther 2008;27:678-684.

188. Ghadir MR, Habibinejad H, Heidari A, Vahedi H. Doxepin is more effective than nortriptyline and placebo for the treatment of diarrhea-predominant irritable bowel syndrome: a randomized triple-blind placebocontrolled trial. Tehran Univ Med J 2011;69:352-358.
189. Nigam P, Kapoor KK, Rastog CK, Kumar A, Gupta AK. Different therapeutic regimens in irritable bowel syndrome. J Assoc Physicians India 1984;32:1041-1044.

190.Ladabaum U, Sharabidze A, Levin TR, et al. Citalopram provides little or no benefit in nondepressed patients with irritable bowel syndrome. Clin Gastroenterol Hepatol 2010;8:42-48, e1.

191. Talley NJ, Kellow JE, Boyce P, Tennant C, Huskic S, Jones M. Antidepressant therapy (imipramine and citalopram) for irritable bowel syndrome: a double-blind, randomized, placebo-controlled trial. Dig Dis Sci 2008;53:108-115.

192. Andresen V, Camilleri M, Busciglio IA, et al. Effect of 5 days linaclotide on transit and bowel function in females with constipation-predominant irritable bowel syndrome. Gastroenterology 2007;133:761-768.

193. Johnston JM, Kurtz CB, Macdougall JE, et al. Linaclotide improves abdominal pain and bowel habits in a phase IIb study of patients with irritable bowel syndrome with constipation. Gastroenterology 2010;139:18771886, e2.

194. Castro J, Harrington AM, Hughes PA, et al. Linaclotide inhibits colonic nociceptors and relieves abdominal pain via guanylate cyclase-C and extracellular cyclic guanosine 3',5'-monophosphate. Gastroenterology 2013;145:1334-1346.

195. Yang Y, Fang J, Guo X, et al. Linaclotide in irritable bowel syndrome with constipation: a phase 3 randomized trial in China and other regions. J Gastroenterol Hepatol 2018;33:980-989.

196. Rao S, Lembo AJ, Shiff SJ, et al. A 12-week, randomized, controlled trial with a 4-week randomized withdrawal period to evaluate the efficacy and safety of linaclotide in irritable bowel syndrome with constipation. Am J Gastroenterol 2012;107:1714-1724.

197. Chey WD, Lembo AJ, Lavins BJ, et al. Linaclotide for irritable bowel syndrome with constipation: a 26-week, randomized, double-blind, placebo-controlled trial to evaluate efficacy and safety. Am J Gastroenterol 2012;107:1702-1712.

198. Quigley EM, Tack J, Chey WD, et al. Randomised clinical trials: linaclotide phase 3 studies in IBS-C - a prespecified further analysis based on european medicines agency-specified endpoints. Aliment Pharmacol Ther 2013;37:49-61.

199. Shah ED, Kim HM, Schoenfeld P. Efficacy and tolerability of guanylate cyclase-C agonists for irritable bowel syndrome with constipation and chronic idiopathic constipation: a systematic review and meta-analysis. Am J Gastroenterol 2018;113:329-338.

200. Crowell MD, Harris LA, DiBaise JK, Olden KW. Activation of type-2 chloride channels: a novel therapeutic target for the treatment of chronic constipation. Curr Opin Investig Drugs 2007;8:66-70.

201. Fukudo S, Hongo M, Kaneko H, Ueno R. Efficacy and safety of oral lubiprostone in constipated patients with or without irritable bowel syndrome: a randomized, placebo-controlled and dose-finding study. Neurogastroenterol Motil 2011;23:544-e205.

202. Johanson JF, Drossman DA, Panas R, Wahle A, Ueno R. Clinical trial: phase 2 study of lubiprostone for irritable bowel syndrome with constipation. Aliment Pharmacol Ther 2008;27:685-696.

203. Rivkin A, Chagan L. Lubiprostone: chloride channel activator for chronic constipation. Clin Ther 2006;28:2008-2021. 
204.Chey WD, Drossman DA, Johanson JF, Scott C, Panas RM, Ueno R. Safety and patient outcomes with lubiprostone for up to 52 weeks in patients with irritable bowel syndrome with constipation. Aliment Pharmacol Ther 2012;35:587-599.

205. Li F, Fu T, Tong WD, et al. Lubiprostone is effective in the treatment of chronic idiopathic constipation and irritable bowel syndrome: a systematic review and meta-analysis of randomized controlled trials. Mayo Clin Proc 2016;91:456-468.

206. Menees SB, Maneerattannaporn M, Kim HM, Chey WD. The efficacy and safety of rifaximin for the irritable bowel syndrome: a systematic review and meta-analysis. Am J Gastroenterol 2012;107:28-35.

207. Schoenfeld P, Pimentel M, Chang L, et al. Safety and tolerability of rifaximin for the treatment of irritable bowel syndrome without constipation: a pooled analysis of randomised, double-blind, placebo-controlled trials. Aliment Pharmacol Ther 2014;39:1161-1168.

208.Lembo A, Pimentel M, Rao SS, et al. Repeat treatment with rifaximin is safe and effective in patients with diarrhea-predominant irritable bowel syndrome. Gastroenterology 2016;151:1113-1121.

209. Pimentel M, Cash BD, Lembo A, Wolf RA, Israel RJ, Schoenfeld P. Repeat rifaximin for irritable bowel syndrome: no clinically significant changes in stool microbial antibiotic sensitivity. Dig Dis Sci 2017;62:2455-2463.

210.Zhao J, Zheng X, Chu H, et al. A study of the methodological and clinical validity of the combined lactulose hydrogen breath test with scintigraphic oro-cecal transit test for diagnosing small intestinal bacterial overgrowth in IBS patients. Neurogastroenterol Motil 2014;26:794-802.

211. Tan VP, Liu KS, Lam FY, Hung IF, Yuen MF, Leung WK. Randomised clinical trial: rifaximin versus placebo for the treatment of functional dyspepsia. Aliment Pharmacol Ther 2017;45:767-776.

212.Suzuki H, Inadomi JM, Hibi T. Japanese herbal medicine in functional gastrointestinal disorders. Neurogastroenterol Motil 2009;21:688-696.

213.Lembo AJ, Conboy L, Kelley JM, et al. A treatment trial of acupuncture in IBS patients. Am J Gastroenterol 2009;104:1489-1497.

214. Schneider A, Enck P, Streitberger K, et al. Acupuncture treatment in irritable bowel syndrome. Gut 2006;55:649-654.

215.Zhu JJ, Liu S, Su XL, et al. Efficacy of Chinese herbal medicine for diarrhea-predominant irritable bowel syndrome: a meta-analysis of randomized, double-blind, placebo-controlled trials. Evid Based Comple- ment Alternat Med 2016;2016:4071260.

216.Xiao Y, Liu Y, Huang S, et al. The efficacy of Shugan Jianpi Zhixie therapy for diarrhea-predominant irritable bowel syndrome: a metaanalysis of randomized, double-blind, placebo-controlled trials. PLoS One 2015;10:e0122397.

217. Dai YK, Li DY, Zhang YZ, et al. Efficacy and safety of modified Tongxie Yaofang in diarrhea-predominant irritable bowel syndrome management: a meta-analysis of randomized, positive medicine-controlled trials. PLoS One 2018;13:e192319.

218. Fan H, Zheng L, Lai Y, et al. Tongxie formula reduces symptoms of irritable bowel syndrome. Clin Gastroenterol Hepatol 2017;15:1724-1732.

219.Laird KT, Tanner-Smith EE, Russell AC, Hollon SD, Walker LS. Short-term and long-term efficacy of psychological therapies for irritable bowel syndrome: a systematic review and meta-analysis. Clin Gastroenterol Hepatol 2016;14:937-947, e4.

220.Jang AL, Hwang SK, Kim DU. The effects of cognitive behavioral therapy in female nursing students with irritable bowel syndrome: a randomized trial. Eur J Gastroenterol Hepatol 2014;26:918-926.

221.Shinozaki M, Kanazawa M, Kano M, et al. Effect of autogenic training on general improvement in patients with irritable bowel syndrome: a randomized controlled trial. Appl Psychophysiol Biofeedback 2010;35:189198.

222. Ford AC, Talley NJ, Schoenfeld PS, Quigley EM, Moayyedi P. Efficacy of antidepressants and psychological therapies in irritable bowel syndrome: systematic review and meta-analysis. Gut 2009;58:367-378.

223.Zijdenbos IL, de Wit NJ, van der Heijden GJ, Rubin G, Quartero AO. Psychological treatments for the management of irritable bowel syndrome. Cochrane Database Syst Rev 2009:CD006442.

224. Siah KTH, Gong X, Yang XJ, et al. Rome foundation-asian working team report: asian functional gastrointestinal disorder symptom clusters. Gut 2018;67:1071-1077.

225.Holtmann GJ, Talley NJ. Inconsistent symptom clusters for functional gastrointestinal disorders in asia: is Rome burning? Gut 2018;67:19111915.

226. Clevers E, Whitehead WE, Palsson OS, et al. Factor analysis defines distinct upper and lower gastrointestinal symptom groups compatible with Rome IV criteria in a population-based study. Clin Gastroenterol Hepatol 2018;16:1252-1259, e5. 